\title{
Vitrification Technique - New Possibilities for Male Gamete Low-Temperature Storage
}

\author{
E. Isachenko, P. Mallmann, G. Rahimi, J. Risopatròn, \\ M. Schulz, V. Isachenko and R. Sànchez \\ Woman Hospital, University of Cologne \\ Germany
}

\section{Introduction}

According to the recent scientific achievements in cryobiology at present the vitrification belong to perspective technologies.

What is the reason?

Because:

- $\quad$ The method is cheap and quick.

- Due to lowering the temperature of solution's glass transition the permeable cryoprotectants prevents the actual freezing of solution and allows to maintain its some flexibility in a glassy phase.

- Vitrification without permeable cryoprotectants allows to avoid the cryoprotectants toxicity and osmotic stress; the damage of plasmatic and mitochondrial membrane during equilibration with cryoprotectants; protects of plasmatic and mitochondrial membrane against lipid peroxidation and formation of reactive oxygen species and DNA damage.

Cryobiology is a rapidly evolving field which only relatively recently has found broad applications in reproductive medicine. However, as any emerging technology, it has both a great potential and a need for further developments (Petrunkina, 2007).

According to worldwide experience, successful cryopreservation of spermatozoa from different kind of animal including human for long-term storage (cryobanking of genome) or relatively short-term storage (artificial insemination) in conjunction with assisted reproductive technologies allows to promote long-term cryopreservation programmes. The use of programmable or non-programmable "slow" (conventional) freezing (McLaughlin et al., 1990; Yin and Seibel, 1999; Stanic et al., 2000) allows to preserve relatively large volume of diluted ejaculate or prepared spermatozoa from 0.25 to $1.0 \mathrm{~mL}$ with good rates of motility after thawing (Sawetawan et al., 1993; larson et al, 1997) and acceptable levels of integrity of acrosomal and cytoplasmic membranes, in other words with sufficiently high quality postthaw characteristics (Hammadeh et al., 1999; Duru et al., 2001; Meseguer et al., 2004; Isachenko et al., 2003, 2008). It does also provide acceptable protection against membrane changes and destabilization induced by cryopreservation (Glander and Schaller, 2000; Schuffner et al, 2001). 
To avoid the lethal intracellular ice formation, the cryoprotective solution as ruler contains buffers, carbohydrates (glucose, lactose, raffinose, sucrose and trehalose), salts (sodium citrate, citric acid), egg yolk and antibiotics including permeable cryoprotectant glycerol or other cryoprotectives (Mazur, 1963; Barbas \& Mascarenhas, 2009) in combination with comparably slow rates of freezing (Gao et al., 1997) are widely used for these purpose. The aim of slow cooling rates is to maintain a very delicate balance between ice crystal formation and growing concentration of dissolved substances. Conventional freezing procedure for mammalian spermatozoa traditionally includes the following stages of manipulations:

1. slow, step-wise adding of freezing solution to the ejaculate

2. cooling during 20 to $45 \mathrm{~min}$

3. warming in water bath and

4. treatment of spermatozoa by the density gradient or the swim-up procedure

(McLaughlin et al., 1990; Yin and Seibel, 1999; Stanic et al., 2000).

5. The ultimate target of the last manipulation is the removal of permeable cryoprotectants.

As a rule, a pre-requisite for that is a dilution of semen suspension with culture medium in order to reduce the toxicity of permeable cryoprotectant (according to manufacturer's instructions for cryoprotectant of choice). This is associated with additional costs and, not at least, with environmental and adaptation challenges for spermatozoa. In fact, sensitivity of spermatozoa to additional mechanical manipulation is increased after freezing-thawing, and the negative effects of cryopreservation on cell viability and functional competence can be aggravated by additional procedures. The problem is that the addition and, in particular, the removal of permeable osmotically-active cryoprotective agents (permeable cryoprotectants) before cooling and after warming can induce lethal stress due to intracellular ice formation, intracellular eutectic formation or so-called 'dilution (toxic) effects' (Fraga et al., 1991, Petrunkina, 2007) including chilling injury, cytoplasm fracture or even effects on the cytoskeleton (Critser et al., 1988; Fraga et al., 1991; Pérez-Sánchez et al., 1994). The further problems include the chemical toxicity of cryoprotectants and their possible repercussions on the genome or genome- related structures of mammalian spermatozoa (Hammadeh et al., 1999; Gilmore et al., 1997). Moreover, spermatozoa which survive the cryopreservation stress are likely to have undergone subtle functional changes associated with biophysical and biochemical factors influenced by cryoprotectants, which will affect their fertilizing ability (Petrunkina, 2007).

Actually, the problem of the cooling and warming processes is the lethality which closely associated with the intermediate zone of temperature $\left(-10\right.$ to $\left.-60{ }^{\circ} \mathrm{C}\right)$ that cells must traverse twice during cooling and once during warming (Mazur, 1963).

One of relatively recent and much discussed cryobiological emerged technologies within the field of the reproductive cryobiology is the spermatozoa vitrification (cryopreservation by direct plunging into liquid nitrogen). Vitrification is an alternative method that can also be applied to achieve the same purpose and does not use the special extenders. This method is based on the rapid cooling of the cells by immersion into liquid nitrogen, and, thereby, is the key factor reducing the chance of the formation of big ice crystals. In contrast to the programmable ("slow") conventional freezing, vitrification has series of technological advantages useful for the practice: it renders the use of permeable cryoprotectants superfluous and, in addition, is much faster, simpler in application and more cost-effective 
than conventional freezing. In spite of that this method has been investigated extensively and successfully applied to female gametes and embryos of different mammalian species including humans (Rall \& Fahy, 1985; Chen et al., 2001; Reed et al., 2002; Cervera \& GarciaXiménez, 2003; Isachenko et al., 2005b, 2007; Silva \& Berland, 2004), however, it cannot be directly extrapolated to male gametes, due to deleterious osmotic effect of high concentrations of permeable cryoprotectants.

To date, publications dedicated to this topic are rare (Nawroth, et al., 2002; Koshimoto \& Mazur, 2002; Isachenko et al., 2004a, b, 2008). Recent work has reversed this situation in that favorable results have been obtained in human spermatozoa after excluding permeable cryoprotectants from cryopreservation solutions, increasing the cooling rate and using carbohydrates, proteins and other extracellular agents, to increase the viscosity of the surrounding medium of cells and prevent the formation of any intra- and big extracellular crystals (Isachenko et al., 2004a, b). It was shown that permeable-cryoprotectants-free vitrification only with protein (Nawroth et al, 2002; Isachenko et al, 2003, 2004a,b, 2005a) or in combination with sucrose (Isachenko et al., 2008 2011a,b,c,d; Sanchez et al., 2011a, b) as a non-permeable cryoprotectant provides a high recovery rate of motile cells and effectively protects the mitochondrial membrane and the DNA integrity of spermatozoa after warming (Isachenko et al., 2004a, b; 2008). And it is not surprising. According to common point of view the non-permeable cryoprotectants plays the supporting role at permeable cryoprotectants. They binds of extracellular water and at the same time plays anti-toxic role (Kuleshova et al., 1999) decreasing of harmful properties of permeable cryoprotectants. In general, the inclusion of osmotically active, non-permeating compounds into the vitrification solution leads to additional rehydration of cells and, as a result, to decreasing toxic effects of the permeable cryoprotectants on intracellular structures. The non-permeable cryoprotectant sugars possess a unique property: stabilization of a cell membrane (Nakagata \& Takeshima, 1992, 1993; Koshimoto et al., 2000; Koshimoto \& Mazur, 2002).

Also, the application of this modified cryopreservation technique to human spermatozoa allowed to avoid the toxic effect caused by adding and removing of permeable cryoprotectants including the negative effects on the cells' genetic material (Pérez-Sánchez et al., 1994). In our earlier works we have shown that cryopreserved without permeable cryoprotectants human spermatozoa preserved their relatively high motility rate with ability to fertilize oocytes in vitro (Nawroth et al., 2002; Isachenko et al., 2003; 2004a, b). No statistical differences in parameters such as viability, recovery rate or percentage of morphologically normal spermatozoa with undamaged DNA were noted between vitrified and conventionally frozen cells (Nawroth et al., 2002). However, it was observed that the number of cryopreserved spermatozoa displaying features of acrosome reaction was statistically different from that in freshly prepared swim-up spermatozoa (Isachenko et al., 2004a,b, 2005a, 2008, 2011a,b).

In contrast to the programmable (slow) conventional freezing the vitrification renders redundant the need for special cooling programs addition of permeable cryoprotectants. It is much faster, simpler and more cost-efficient while still effectively protecting spermatozoa from cryo-injuries (Nawroth et al, 2002; Isachenko et al, 2003, 2004a, b, 2005, 2008) and does not require expensive equipment or special cooling procedures. Spermatozoa, vitrified by such technology, would be ready for further use without any additional treatment (centrifugation, separation in the gradient, removal of cryoprotectant and others) immediately after thawing. 
Successful pregnancies and births have been reported when using vitrified oocytes and embryos, and vitrification protocols have started to form an important part as well of human as of animal reproductive medicine. Although sperm vitrification techniques have been studied in vitro, first successful pregnancies and live birth after fertilization with vitrified spermatozoa have been reported.

This chapter we would like to present contents the interesting results which we have had in the first time achieved using developed us vitrification technique based on using only of protein and carbohydrates as non-permeable cryoprotectants and applying to some mammalian and fish species.

In our presentation we will not touch the historicalquestions of vitrification of spermatozoa as well, but will concentrate us only on own experience according to vitrification of spermatozoa with using only non-permeable cryoprotectants. This theme was well covered in our previous publications (E. Isachenko et al., 2003, 2008, 2011a; Katkov et al., 2006).

In this chapter we will in detail discuss our new data which we have got in our investigation after vitrification of human, dog and fish spermatozoa.

\section{New capillary technology (Isachenko et al., 2011c) for vitrification of small volume of human spermatozoa and practical application}

Varied methods to vitrify spermatozoa have been described previously: cryo-loops, droplets- and open pulled straw method (Nawroth et al, 2002; Isachenko et al., 2004a,b, 2005,2008 ). According to these results it is possible to achieve up to $60 \%$ - and $20 \%$-motility levels after thawing in normospermic and oligo-astheno-terato-zoospermic patients, respectively, depending on vitrification method selected and the quality of the original ejaculate. Independent from the vitrification technique the vitrified spermatozoa can be processed for further use immediately after warming without additional treatment such as centrifugation, gradient separation, removal of cryoprotectants etc is required. This simplicity for practical purposes represents one of the most attractive advantages of our technology. It is worth to mention that the protocol for vitrification does include swim up treatment, therefore, after swim up, vitrification and warming spermatozoa are also free from seminal plasma with potential pathogens. "Slow" freezing of human spermatozoa traditionally proposes the removing of permeable cryoprotectant after thawing.

This «removal of permeable cryoprotectants» is the ultimate target of the last manipulation. As a rule, a pre-requisite for that is a dilution of semen suspension with culture medium in order to reduce the toxicity of permeable cryoprotectant (according to manufacturer's instructions for cryoprotectant of choice). This is associated with additional costs and, not at least, with environmental and adaptation challenges for spermatozoa. In fact, sensitivity of spermatozoa to additional mechanical manipulation is increased after freezing-thawing, and the negative effects of cryopreservation on cell viability and functional competence can be aggravated by additional procedures (Petrunkina, 2007). Cryopreservation induces extensive damage to cells during both freezing and thawing. According to present knowledge, the effective induction of anabiosis in cells at very low temperatures (in liquid nitrogen at $-196^{\circ} \mathrm{C}$, for example) can be achieved by optimizing the multi-factorial freezing process (Lozina-Lozinski, 1982), commonly with the use of permeable cryoprotectants (Levin, 1982). Acting by depressing the freezing point and by 
binding intracellular water, the permeable and non-permeable cryoprotectants help to prevent ice formation, and thereby to reduce the cryo-damage (Andrews, 1976; Franks, 1977).

Several protocols of spermatozoa separation are available (e.g. swim-up from the ejaculate, single wash of ejaculate and swim-up from pellet, double wash of ejaculate and swim-up from pellet). However, any methodology needs the use of previous centrifugation. Most of the current technologies for sperm vitrification have an obvious shortcoming in terms of standardization of the portion volume. In particular, as the diameter of the pulled part of straw is not uniform, the volumes of the portions packaged in that way can not be standardized. Here we have reported the vitrification methodology using standard capillaries which can be supplied by industrial manufacturers. The technique was performed as follow (Isachenko V et al., 2011c). All specimens used for this study had fulfilled following quality criteria for spermatozoa concentration, motility and morphology: less than 20 millions spermatozoa/mL, $35 \%$ progressive motile and minimum $3 \%$ morphologically normal spermatozoa. Semen analysis was performed according to published guidelines of the World Health Organization (WHO, 1999). Prior to vitrification, the sedimented spermatozoa were diluted with $0.25 \mathrm{M}$ sucrose (end concentration) in sperm preparation medium at room temperature (Isachenko et al., 2008). The final concentration of spermatozoa was approximately of $0.5 \times 10^{6}$ spermatozoa $/ \mathrm{mL}$. Diluted suspensions were maintained at room temperature for $5 \mathrm{~min}$ before the cooling procedure. Spermatozoa were prepared and portioned for aseptic vitrification in the following way. Specially for our purposes, $50 \mu$ L-plastic capillaries (Fig.1) were manufactured from hydrophobic material as vehicles for cooling sperm cell suspensions (Gynemed GmbH \& Co. KG, Lensahn, Germany). The end of the straw was labeled on the top to mark the cutting-off position (Fig.1, arrows). The capillary was filled with $10 \mu \mathrm{L}$ of spermatozoa suspension by aspiration (Fig. 1a). It was absolutely crucial to avoid that the inner surface of the capillary become moist during packaging procedure. Aspirating the volume of sperm cell suspension above the mark and correcting it by lowering the fluid level inside the capillary after aspiration is technologically wrong and would result in excess of portion's volume after thawing. After the aspiration was completed, the capillary was inserted into $0.25 \mathrm{ml}$ straw (Medical Technology $\mathrm{GmbH}$, Bruckberg, Germany). One end of this straw was sealed in advance using heat-sealer (Cryo Bio System, Paris, France). After sealing the second end of the straw (Fig. 1b), the straw was plunged into liquid nitrogen and cooled at a cooling speed of $600^{\circ} \mathrm{C} / \mathrm{min}$. The speed of cooling was determined using a Testo 950 electrical thermometer (Testo AG, Lenzkirch, Germany) using $0.2 \mathrm{~mm}$ electrode located inside of the capillary. Hermetical heat-sealing of $0.25 \mathrm{~mL}$ straw can be achieved using flame of alcohol burner and forceps or any commercial equipment (including ultrasound equipment because of large distance between spermatozoa suspension and focus of sonographic appliance). Spermatozoa were stored in liquid nitrogen at least for $24 \mathrm{~h}$ before warming. For warming, capillary was removed from isolating $0.25 \mathrm{~mL}$ straw. The straw was disinfected with ethanol in the area where the marked end of capillary was (Fig. 1, arrows). The second end of capillary is fixed tightly on the inner surface of the straw, and the part of straw containing spermatozoa is still half submerged in liquid nitrogen (Figs. 1c,d). The upper part of the straw was cut off with sterile scissors as close as possible to the marked end of the capillary, just above the mark without touching the marked end of capillary. The capillary 
was expelled with a conical bolt (Fig. 1d). For this purpose, conical bolt (instead the conical bolt forceps can be used in place) is inserted into inner part of the capillary and pulled off the straw. The final warming up of spermatozoa is achieved by immersing of capillary without conical apex (capillary must be open from both sides) with vitrified spermatozoa into $1.8 \mathrm{~mL}$ centrifuged tube with $0.7 \mathrm{~mL}$ pre-warmed to $37^{\circ} \mathrm{C}$ vitrification medium for approximately $20 \mathrm{sec}$. (Fig. 1e). It is important to note that the volume of vitrified suspension after warming is not decreased (Fig 1e). Finally, the suspension of spermatozoa was expelled from the capillary for immediate evaluation of spermatozoa quality. Using this technique the exactly quantifiable volumes of spermatozoa samples were obtained: $10 \mu \mathrm{L}$ suspension of spermatozoa were vitrified, $10 \mu \mathrm{L}$ were thawed and the same $10 \mu \mathrm{L}$ added to the respective volume of medium for ICSI or IVF. Thus, one of the most important features of this novel method of vitrification in capillaries is its potential for standardization which can be used for the routine clinical practice. The results of the present study let suggest that cryopreservation by vitrification helps to preserve essential determinants of spermatozoa function, such as motility and plasma membrane integrity. It is well known that spermatozoa cryopreservation is associated with a large decline in spermatozoa viability and other sperm functional parameters (Petrunkina, 2007). In the present study we have compared spermatozoa quality after vitrification by our method with spermatozoa quality after conventional freezing with addition of permeable cryoprotectant. The outcomes indicated that vitrification in capillaries compare to conventional freezing preserved better the motility of spermatozoa (after warming/thawing: $28.0+6.0 \%$ vs $18.0+9.2 \%$, respectively, $\mathrm{P}<0.05$ and in fresh control $35.0+9.5 \%$; after $24 \mathrm{~h}$ in vitro culture: $12.0+2.8 \%$ vs $5.0+3.1 \%$, respectively, $\mathrm{P}<0.05$ and in fresh control $20.0+3.9 \%$; after $48 \mathrm{~h}$ in vitro culture: $6.0+1.0 \%$ vs $0.5+0.02$ $\%$, respectively $\mathrm{P}>0.1$ and in fresh control $10.0+1.9 \%$ [Fig. 2]) and their plasma membrane integrity $(56.0 \pm 5.1 \%$ vs $22.0 \pm 3.5 \%$, respectively, $\mathrm{P}<0.05$ and in fresh control $96.0 \pm 0.6$ $\%, \mathrm{P}<0.05$ [Figure 3]) which was assessed with LIVE / DEAD sperm viability kit (LIVE/DEAD Sperm Viability Kit, Molecular Probes cat no. L-7011, Eugene, OR, USA). Pilot results have been obtained with respect to evaluating capacitation-like changes associated with cryopreservation, so called "cryo-capacitation" (Cormier and Bailey, 2003). A body of evidence suggests that some spermatozoa' intracellular signaling pathways can be affected during cryopreservation, and after warming spermatozoa display features commonly observed in capacitating or capacitated spermatozoa (Green and Watson, 2001; Petrunkina et al., 2005; Vadnais and Roberts, 2010). It is important, however, to emphasize that the changes induced by cryo-preservation are similar to those of capacitation only at the functional level, and they seem to differ at the molecular level, and with respect to pathways and signaling mechanisms involved (Cormier and Bailey, 2003). Our observations imply that permeable cryoprotectant-free aseptic vitrification is associated with lesser damage to acrosomes compare to conventional freezing (55.0 \pm 5.8 $\%$ vs $21.0 \pm 3.8 \%$, respectively, $\mathrm{P}<0.05$ and in fresh control $84.0 \pm 3.1 \%, \mathrm{P}<0.05$ [Fig. 4]). However, the levels of membrane changes related to "cryo-capacitation" assessed by CTC in vitrified spermatozoa were comparable with those after conventional freezing $(8.0 \pm$ $1.1 \%$ vs $9.0 \pm 2.2 \%$, respectively, $\mathrm{P}<0.01$ and in fresh control $2.0 \pm 0.3 \%, \mathrm{P}<0.05$, [Figure 5]). Changes in the acrosomal membrane status and permeability associated with the capacitation we have evaluated by using the double fluorescence chlortetracycline (CTC)Hoechst 33258 staining technique (Kay et al, 1994). Nevertheless, the exposure to low temperatures can affect those crucial signaling mechanisms which can not be monitored 
by CTC. Thus, further studies with additional, advanced techniques are needed to investigate the changes induced by vitrification in its complexity (e.g. targeting specific pathways and membrane processes such as changes in lipid architecture and/or protein kinases/phosphatases regulated pathways). Given the fact that the outcome of basic spermatozoa quality was comparable (or even better) that after conventional freezing, other advantages of the vitrification process must be taken into account. During conventional procedure, the success of applying permeable cryoprotectants for cryopreservation of varied cells and tissues is inseparably linked to such cryoprotectant properties as their ability to permeate rapidly through cellular membrane and their toxicity (Gilmore et al, 1997). These properties are directly connected to osmotic damages of cells during saturation with permeable cryoprotectants before freezing and then at time of cryoprotectants removing after thawing (Gao et al, 1995, Petrunkina, 2007). It is known that human spermatozoa contain large quantities of proteins, sugars, and other components that may act as natural cryoprotectants. Our technology does not presuppose the use of permeable cryoprotectant. In practical terms, permeable cryoprotectant-free vitrification technology for the cryopreservation of spermatozoa (in straws) instead traditional slow freezing with permeable cryoprotectants is already used in following centers: our university's maternity hospital (www.uniklinik-ulm.de): IVF Centers in Temuco, Chile (about 200 IUI cycles/year) and in Ulm, Germany (www.kinderwunschulm.de) (about 1,000 IVF cycles/year). First successful pregnancies and birth of healthy babies has been recently achieved with spermatozoa vitrified without permeable cryoprotectants (Isachenko et al., 2011b). In summary, the newly developed technology of aseptic vitrification of human spermatozoa in capillaries can effectively preserve these cells from cryo-injures. Spermatozoa, vitrified by this technology, are free from seminal plasma owing to swim up procedure preceding vitrification and are free from permeable cryoprotectants. They are ready for further use immediately after warming without any additional treatment. Therefore, the reported technology has a great potential for use in ICSI / IVF.

As successful application of this vitrification technology for routine practice is born of two healthy babies (Isachenko et al., 2011b). We would like shortly present here the history of this case. A couple, both 39 years old, underwent assisted reproduction due to severe endometriosis and oligo-astheno-terato-zoospermia $\left(13 \times 10^{6}\right.$ motile spermatozoa/ml; with $42 \%$ of progressive motility and $8 \%$ morphologically normal spermatozoa [WHO, 1999]). Cryopreserved spermatozoa were used because the partner was absent during the oocyte retrieval procedure. The swim up-processed spermatozoa were diluted and proceeded with vitrification solution according our technique, described above, to achieve a final concentration of $2,5 \times 10^{6}$ spermatozoa/ml and $10 \mu \mathrm{l}$ aliquots were vitrified with using of Cut-Standard-Straws (CSS, Isachenko et al., 2007) which was chosen as the prototype of our capillary technology. The spermatozoa were kept frozen in liquid nitrogen (at $-196^{\circ} \mathrm{C}$ ) for 7 months. Only the warming technique was different from newly developed one and supposed the concentrations of spermatozoa by centrifugation after warming. The changes in following physiological and morphological parameters of thirty minutes after warming of vitrified spermatozoa and the freshly prepared swim-up were investigated for progressive motility, capacitation-like membrane changes due to determining of phosphatidylserine translocation (PST). The capacitation-like membrane changes was investigated due to determining of phosphatidylserine translocation (PST) in the sperm with appling the anexin V-FITC staining technique (APOPTESTTM-FITC, Nexins Research, the Netherlands). 

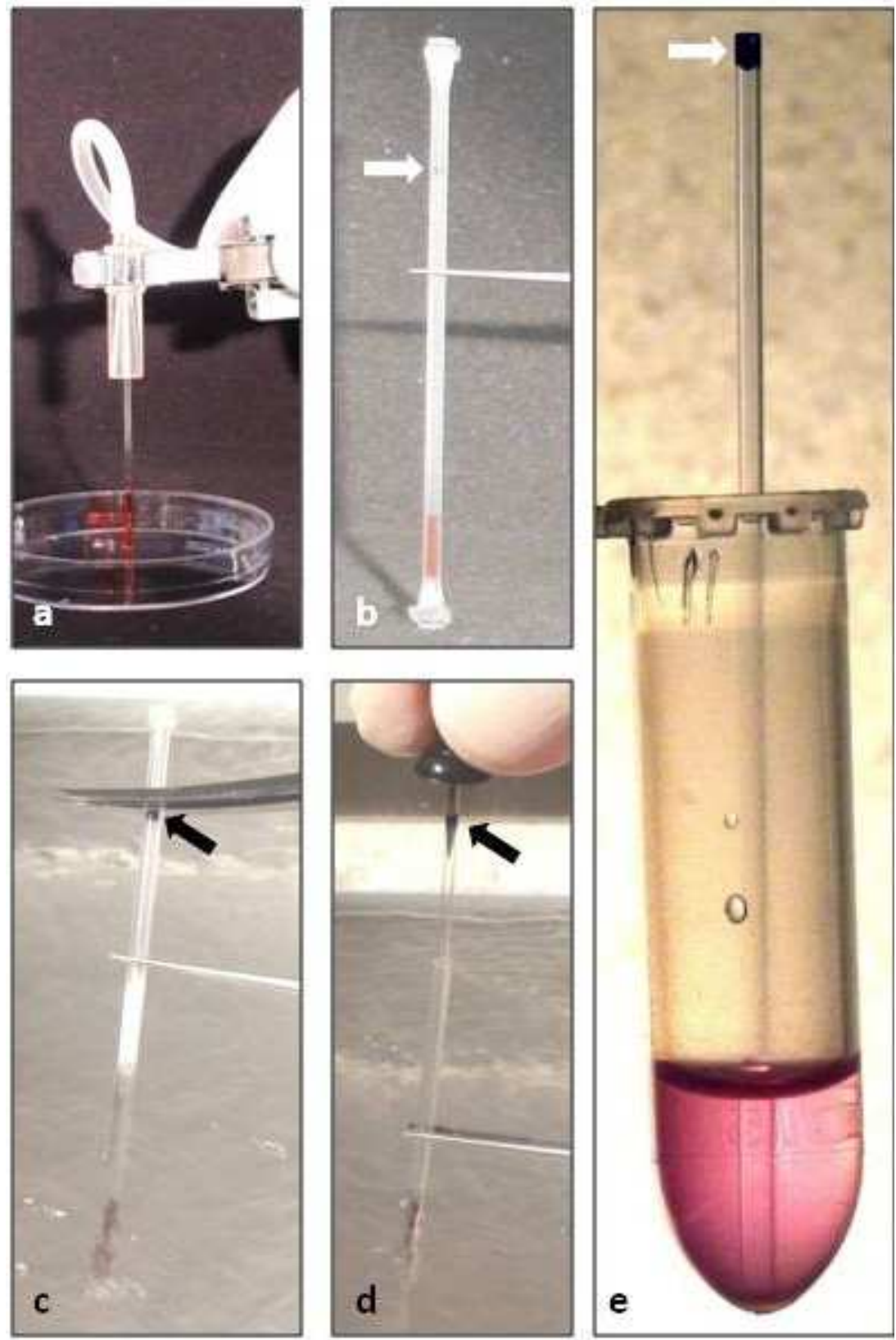

(Arrows) marked end of $50 \mu \mathrm{L}$ capillary, (a) aspiration of spermatozoa suspension in straw, (b) $50 \mu \mathrm{L}$ capillary sealed in $0.25 \mathrm{~mL}$ straw, (c) cutting of $0.25 \mathrm{~mL}$ straw, (d) expelling of $50 \mu \mathrm{L}$ capillary from $0.25 \mathrm{~mL}$ straw, (e) warming of spermatozoa.

Fig. 1. Schematic illustration of human spermatozoa vitrification with $50 \mu \mathrm{L}$ capillary. 


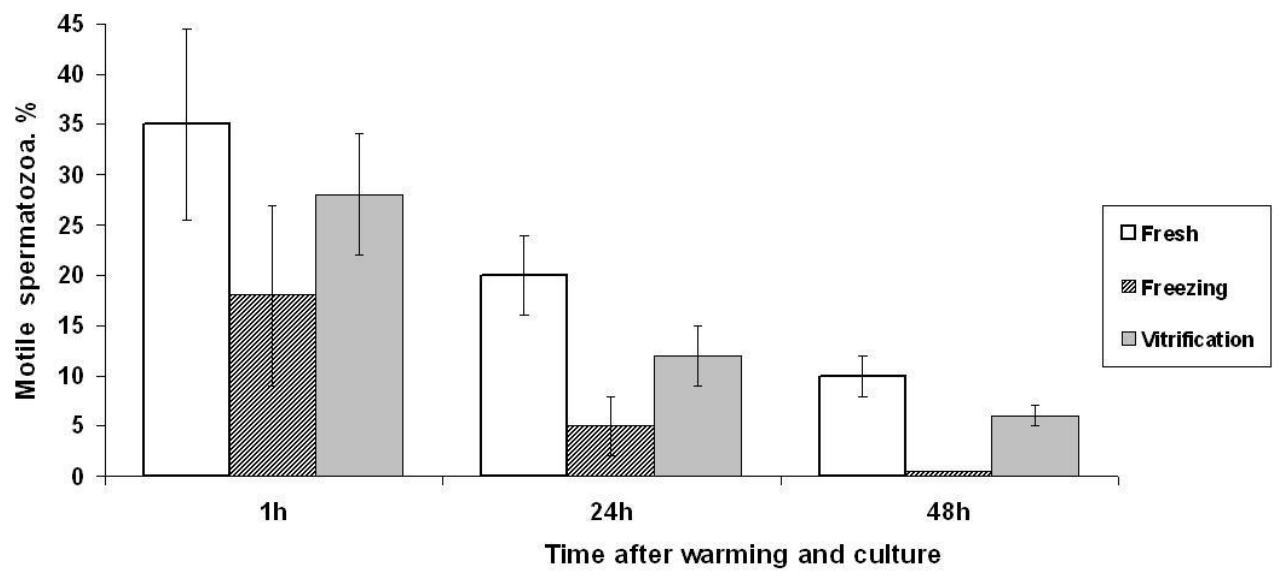

All rates in respective groups are significantly different $(\mathrm{P}<0.05)$.

Fig. 2. Motility of human spermatozoa after conventional freezing and vitrification.

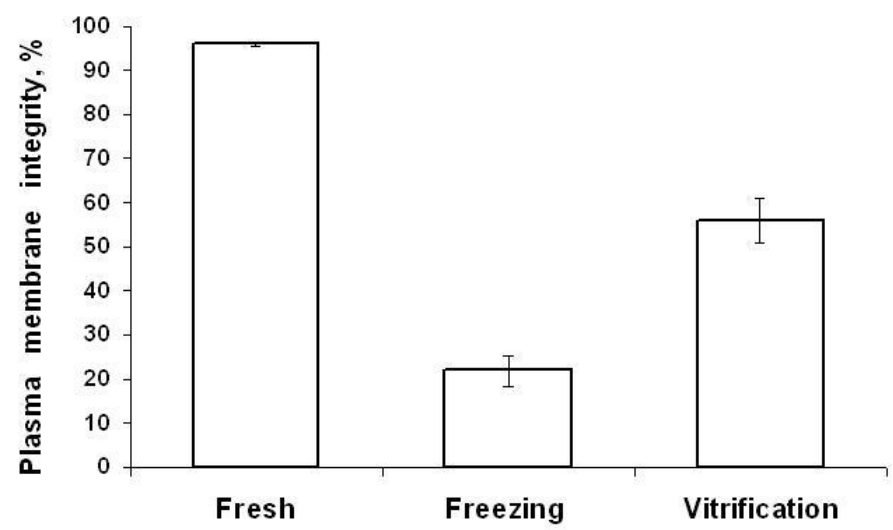

All rates in respective groups are significantly different $(\mathrm{P}<0.05)$.

Fig. 3. Plasma membrane integrity of human spermatozoa after conventional freezing and vitrification. 


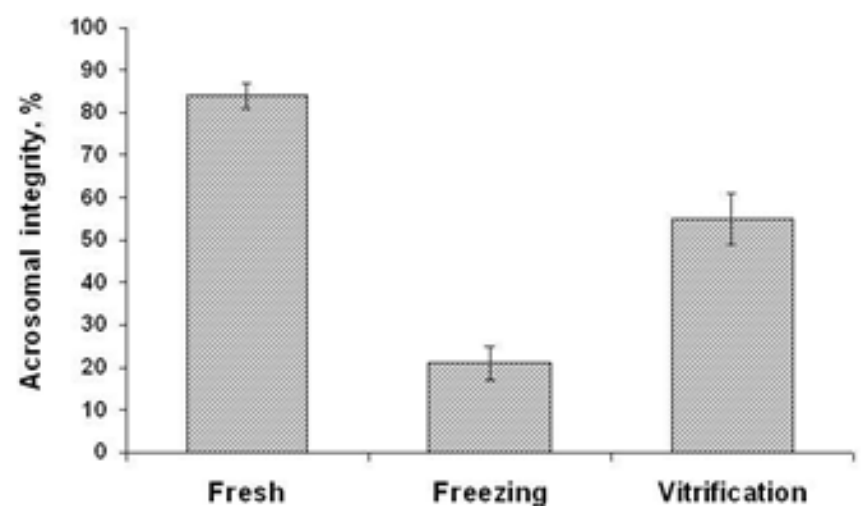

All rates in respective groups are significantly different $(\mathrm{P}<0.05)$.

Fig. 4. Acrosomal integrity of human spermatozoa after conventional freezing and vitrification.

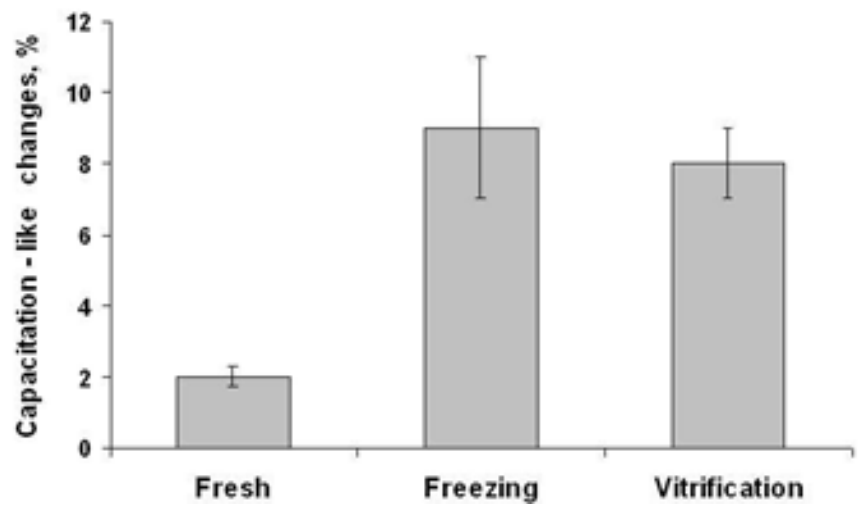

Rates in groups after freezing and vitrification are similar $(\mathrm{P}>0.5)$.

Fig. 5. Capacitation-like changes of human spermatozoa after conventional freezing and vitrification.

The mitochondrial membrane potential integrity was evaluates due to measurement of the changes in the $(\mathrm{M} \Delta \Psi)$ using a unique fluorescent cationic dye, 5, 5', 6, $6^{\prime}$-tetachloro-1-1', 3, $3^{\prime}$ tetraethyl-benzamidazolocarbocyanin iodide. The results were as following: progressive motility $60 \%$ vs $90 \%$, correspondingly, $10 \%$ were identified as displaying a 'capacitation' CTC pattern and 5\% as displaying an 'acrosome reaction' pattern, as compared to $8 \%$ and $5 \%$ in freshly prepared swim-up sperm respectively; $63 \%$ of spermatozoa were classified as having high mitochondrial membrane potential (vs $96 \%$ in freshly prepared spermatozoa).

From ten ICSI-ed with vitrified spermatozoa oocytes 6 oocytes showed signs of normal fertilization and two PN-oocytes were culture subsequent 24 hours. At day of embryo transfer two 4-blastomere embryos of Grades " $a$ " (4a) and " $b$ " (4b) (Steer et al., 1992) were 
transferred to the uterus cavity under ultrasonographic guidance. Fifteen days after embryo transfer, the maternal $\mathrm{B}$-hCG level was $360 \mathrm{IU} / \mathrm{L}$ and two healthy boys were born at term.

These data supports the notion that: i) cells can be frozen effectively without toxic permeable cryoprotectants, and ii) such frozen material could in principle be lyophilized. It is, however, critical to ensure that freeze-drying is not associated with the genetic and developmental abnormalities that have been observed after fertilization with mouse freezedried sperm (Ward et al., 2003).

Cryopreservation is normally achieved through a tertiary combination of cells, permeable cryoprotectants and low temperature environment. In contrast, our cryopreservation protocol can be considered as a simplified binary combination of cells (in a simplified medium containing sucrose as a natural cryoprotectant) and a cold environment. The birth of two healthy babies using this in vitro fertilization technique is not only the first report on successful fertilization using vitrified spermatozoa (which has obvious practical advantages for assisted reproduction techniques). The above protocol also demonstrates that highly organized cells (human spermatozoa) may be effectively frozen-dried (lyophilized) with the recovery of their most important physiological function after thawing - propagation of genetic hereditary information and subsequent birth of new individuals. Of course, it would need to be proved on a large number of ejaculates that the damage produced by vitrification does not exceed the damage produced by conventional freezing and that there are no deleterious effects on the genetic integrity of sperm after vitrification (Ward et al., 2003). These aspects, however important, are outside the scope of this case report.

\section{New technology for vitrification of spermatozoa in big volume (Isachenko et al., 2011d)}

Actually, the technique which is not acceptable for different volumes of the same object is incomplete and needs subsequent investigations and development. In this case the next aim of our research was development the acceptable vitrification methodology for big volume of spermatozoa with possibility to use cryopreserved ejaculate for intrauterine insemination. At the beginning of 2011 we have published (E. Isachenko et al., 2011a) the prototype of our big-volume vitrification technology the success of which a healthy baby was born after intrauterine insemination with vitrified spermatozoa (Sánchez et al., 2011a). We would like shortly present the history of this case. A 39-year-old patient and her 35-year-old husband, with a 3-year history of primary infertility, were referred to our center for infertility treatment. Laparoscopy revealed patency of the Fallopian tubes and no evidence of endometriosis or pelvic adhesions. Semen analysis of the husband showed oligo-asthenoterato-zoospermia (WHO, 1999). Despite the poor quality of ejaculate parameters, for financial reasons the patients decided to try intra-uterine insemination (IUI). For IUI the spermatozoa from two ejaculates obtained 3 days apart were vitrified. The volume of the first ejaculate was $1.9 \mathrm{ml}$, concentration $37.8 \times 10^{6}$ spermatozoa/ml, $8 \%$ of progressive "a" and " $\mathrm{b}$ " motility, $10 \%$ of morphologically normal spermatozoa, and $0.2 \times 10^{6}$ round cells $/ \mathrm{ml}$. The volume of the second ejaculate was $3.9 \mathrm{ml}$, concentration $11.2 \times 10^{6}$ spermatozoa/ml, $27 \%$ progressive motility, $10 \%$ of morphologically normal spermatozoa and $1.2 \times 10^{6}$ round cells $/ \mathrm{ml}$. The swim up-processed spermatozoa were diluted and proceeded with vitrification solution according our technique, described above, to achieve a final 
concentration of $1 \times 10^{6}$ spermatozoa/ml. All subsequent manipulations were performed at room temperature strictly in a horizontal position to prevent a loss of suspension (E. Isachenko et al., 2011a). Aliquots $(100 \mu \mathrm{l})$ of the diluted sperm suspension were aspirated into one half of $0.25 \mathrm{ml}$ plastic straws (MTG, Bruckberg, Germany); these were then placed in $0.5 \mathrm{ml}$ plastic straws (MTG) and hermetically sealed from both sides to protect the suspension from direct contact with liquid nitrogen. The closed straw-systems, strictly maintained horizontal, were then immersed into liquid nitrogen and stored until use. From two ejaculates three straws were cryopreserved, each with $100 \mu \mathrm{l}$ of spermatozoa suspension in concentration of $1 \times 10^{6}$ spermatozoa/ml. Special for this case we have decided to investigate the presence of reactive oxygen species (ROS) in ejaculated and prepared spermatozoa before and after vitrification. The reason was the following. It is known that poor ejaculate quality is closely associated with elevated concentrations of leucocytes (normal values $<1$ million/ml). The presence of leucocytes can lead to oxidative stress (Henkel and Schill, 2003; Henkel et al., 2005, 2010). Therefore, we determined the concentration of leucocytes in ejaculates due to leucocytes quantifying by an indirect immunofluorescence (IIF) method (Villlegas et al., 2002) and presence of the following antibodies were checked: anti CD45 for all leukocytes (M 855-DAKO, Hamburg, Germany, in concentration of 1/50 in PBS with 5\% BSA), anti CD15 for granulocytes (M 733-DAKO, Hamburg, Germany, in concentration of $1 / 100$ in PBS with 5\% BSA) or anti CD68 for macrophages (M 718-DAKO, Hamburg, Germany, in concentration of 1/600 in PBS with $5 \%$ BSA). However, in spite of the presence of a large numbers of round cells, the IIF was negative for all tested monoclonal antibodies, indicating high levels of spermatogenic cells. The presence of ROS in ejaculates was tested using a chemiluminescence assay (Aitken and Clarkson, 1987). Only the mild increasing of ROS to 76.960 RLU x $10^{7} /$ live sperm was noted (normal value: 35.000 RLU x 107/live sperm (Henkel et al, 1997). However, it is known that ROS in semen samples of oligozoospermic patients usually is slightly increased (Kumar et al., 2009). On the day of ovulation all three cryopreserved samples of spermatozoa suspension were thawed as described in E. Isachenko et al. (E. Isachenko et al., 2011a), the sperm pellet was resuspended in $500 \mu \mathrm{l}$ of sperm preparation medium pre-warmed to $37^{\circ} \mathrm{C}$ and used immediately for intrauterine insemination. The suspension of spermatozoa before insemination (30 min post-warming) had a concentration of $2.7 \times 10^{6}$ spermatozoa/ml with $60 \%$ of progressive motility. Fifteen days after IUI, biochemical pregnancy was confirmed by B-hCG level of 125 IU/L and on 29 December 2010 a healthy male baby was born.

Our finding has confirmed that the aseptic vitrification technique (without use of permeable cryoprotectants) is not only instrumental in effectively preserving spermatozoal function (Isachenko et al., 2011a, b, c, d, Sánchez et al., 2011), but could also have a massive potential for storage of motile spermatozoa for intrauterine insemination, for example, in cases of oligo-astheno-zoospemic patients.

However, the described methodology for vitrification of big-volume spermatozoa suspension is complicated, because exist often dangerous that sperm suspension will flows out the specimen straw and stick together to the inner wall of packaging straw during vitrification procedure. In this case it will be difficult to remove the specimen straw from the packaging one before warming. According to our opinion the technique must be as simple as possible and at the same time with absolute repeatability and the results have to be compatible with slow conventional freezing. 
In our lectures we have often mentioned that there is a simplified point of view that vitrification is the solidification without formation of crystals. Extending this description, one could say that vitrification is solidification of vitrifying solution without formation of hexagonal (big, lethal) intracellular structures by extreme elevation in viscosity during cooling. Obviously, thereby vitrification appears beneficial in terms of avoiding cryo-injuries traditionally associated with the formation of intracellular ice. Therefore we developed and for the first time reported (V. Isachenko et al., 2011d) the vitrification methodology where a relatively large volume of spermatozoa suspension can be frozen in one cooling pocket (straw). Vitrification medium described here does include sucrose (Isachenko et al., 2008). As a rule, in routine practice the carbohydrates are the standard part of any cryoprotective solution. They are used for spermatozoa cryopreservation to compensate osmotic effects caused by the permeable cryoprotectants and do play an important role as an additional dissolving, membrane stabilizing and dehydrating agents (Wakayama et al., 1998). Therefore, sucrose can be considered as a natural cryoprotectant, lacking most of toxic properties of permeable cryoprotectants. Human spermatozoa can be successfully frozen in the absence of permeable cryoprotectants, using protein- and sugar-rich extracellular nonpermeable cryoprotectants (Koshimoto et al., 2000; Karlsson and Cravalho, 1994). The ability of sucrose to prevent the artificial induction of membrane damages and acrosome reaction during vitrification/warming (Isachenko et al., 2008) corroborated our previous conclusions that the inclusion of sucrose in combination with human serum albumin in the vitrification medium has a visible cryoprotective effect.

In our study (Isachenko et al., 2011d) we reported for the first time a novel technology of aseptic 'cryoprotectant-free' vitrification of human spermatozoa in large volumes. It allows:

1. to obtain $0.5 \mathrm{~mL}$ of spermatozoa suspension, free both from seminal plasma (because of swim up procedure preceding vitrification) and free from additives which are part of conventional freezing procedures;

2. to cryopreserve spermatozoa, which are ready for further use immediately after thawing without any additional treatment (centrifugation, separation in the gradient, removal of cryoprotectant and others).

The technology includes:

- cryoprotective medium with only non-permeable cryoprotective agents (0,25 M sucrose in end concentration and $1 \%$ human serum albumin). As basal medium is the Human Tubal Fluid (Quinn et al., 1985).

- the end-concentration of prepared for vitrification spermatozoa is $5 \times 10^{6}$ spermatozoa / $\mathrm{mL}$. It is possible to vitrify the different concentrations of prepared spermatozoa without influence on warming resalts (non-published data).

- $\quad$ using of $0.5 \mathrm{~mL}$ plastic straws with subsequent sealing from both side before cooling in liquid nitrogen.

- The warming up of spermatozoa is achieved by immersing straw with vitrified spermatozoa into warmed water bath at $42^{\circ} \mathrm{C}$.

\section{Technological procedure, shortly}

Vitrification. Prior to vitrification, spermatozoa were processed by swim-up technique with subsequent dilution with cryoprotectant medium according to Isachenko (Isachenko et al., 
2008). Diluted suspensions were maintained at room temperature for 5 minutes before the cooling procedure. The packaging of spermatozoa for aseptic vitrification was performed in the following way. Spermatozoa suspensions were cooled in $0.5 \mathrm{~mL}$ plastic CBS straws (CryoBio System, Paris, France) (Figure 6). The straw was labeled with asterisk $(1 \mathrm{~cm}$ from the inner end of cotton-polyvinil plunge, arrows on Figures 6a-g). The straw was filled up to asterisk with $0.5 \mathrm{~mL}$ of spermatozoa suspension by aspiration (Figure 6a). Then the filled straw was expelled from the tube while aspiration of air continued. Subsequently, when the suspension reached the polyvinyl plunge, the polymerization of polyvinyl was initiated due to humidification. After aspiration was completed, and the top end of straw was sealed by polymerized polyvinyl, straw was hermetically heat-sealed at both sides using flame of alcohol burner and forceps (Figures 6b,e). The hermetically sealed straw with spermatozoa was allowed to cool briefly ( $\sim 2$ seconds). This procedure ensured that spermatozoa at any time were not in contact with the heat-sealing area. Alternatively, any commercial equipment (with exception of ultrasound equipment) could be used for thermo-hermetic sealing. The straws were immersed into liquid nitrogen in horizontal position (approximately for 8 seconds) (Figure 6c) and stored there at least for 24 hours before use.

Warming. The warming up of spermatozoa is achieved by immersing straw with vitrified spermatozoa into water bath at $42^{\circ} \mathrm{C}$ and dangling it gently in water for 20 seconds (Figure 6 d). After warming, the residual fluid was removed from the straw with paper towel, and straw disinfected with $70 \%$ ethanol. The heat-sealed part of straw (opposite to the cottonpolyvinyl plunge) was cut off with sterile scissors, and the aspirator was connected with the straw (Figure 6f). A low differential negative pressure was applied by aspiration. That ensured that after subsequent cutting of the cotton-polyvinyl plunge fluid was not leaking out (Figure 6f). Finally, the suspension was expelled from the straw (Figure 6g) for immediate evaluation of sperm quality, loading into catheter and intrauterine insemination.

The results were compared to slow frozen spermatozoa. For this purpose the Freezing Medium TYB, IrvineScientific, with 12 \% (v/v) glycerol and $20 \%$ (v/v) egg yolk were used. The suspension of swim up-prepared spermatozoa was 1:2 diluted with freezing medium (to achieve the concentration of $0.5 \times 10^{6}$ spermatozoa / $\mathrm{mL}$ and equilibrated at room temperature for 10 minutes then the $500 \mu \mathrm{L}$ of spermatozoa suspension was packaged into $0.5 \mathrm{~mL}$ plastic straws (Cryo Bio System, Paris, France), the straws were sealed from both sides, kept in horizontal position at $4{ }^{\circ} \mathrm{C}$ for 30 minutes and put in the horizontal position into liquid nitrogen vapor $\left(-80^{\circ} \mathrm{C}, 10 \mathrm{~cm}\right.$ over liquid nitrogen surface), kept for 30 minutes and finally placed into liquid nitrogen where they were stored minimum 24 hours until evaluation. For thawing of samples, the straws were taken from liquid nitrogen, hold in air for 30 seconds, immersed into $37^{\circ} \mathrm{C}$ water bath in horizontal position and hold in this bath for 20 seconds until ice melted. After thawing, $10 \mathrm{~mL}$ of basic (HTF-HSA) medium was added to thawed sample and centrifuged for 5 minutes at $340 \mathrm{~g}$. The supernatant was removed and pellet resuspended with the same basic medium in order to obtain a final concentration of $0.5 \times 10^{6}$ spermatozoa/mL. The changes in following physiological and morphological parameters of thirty minutes after warming of fresh, vitrified and conventional frozen spermatozoa were investigated for progressive motility (WHO, 1999); cytoplasmic membrane integrity (CMI) with applying of a LIVE/DEAD sperm viability kit, which is used to stain nucleic acid probe molecular (SYBR-14 dye) and propidium iodide (IP) and Acrosomal membrane integrity (AMI). The acrosome-reacted, and capacitated spermatozoa were detected using the double fluorescence chlortetracycline (CTC)-Hoechst 


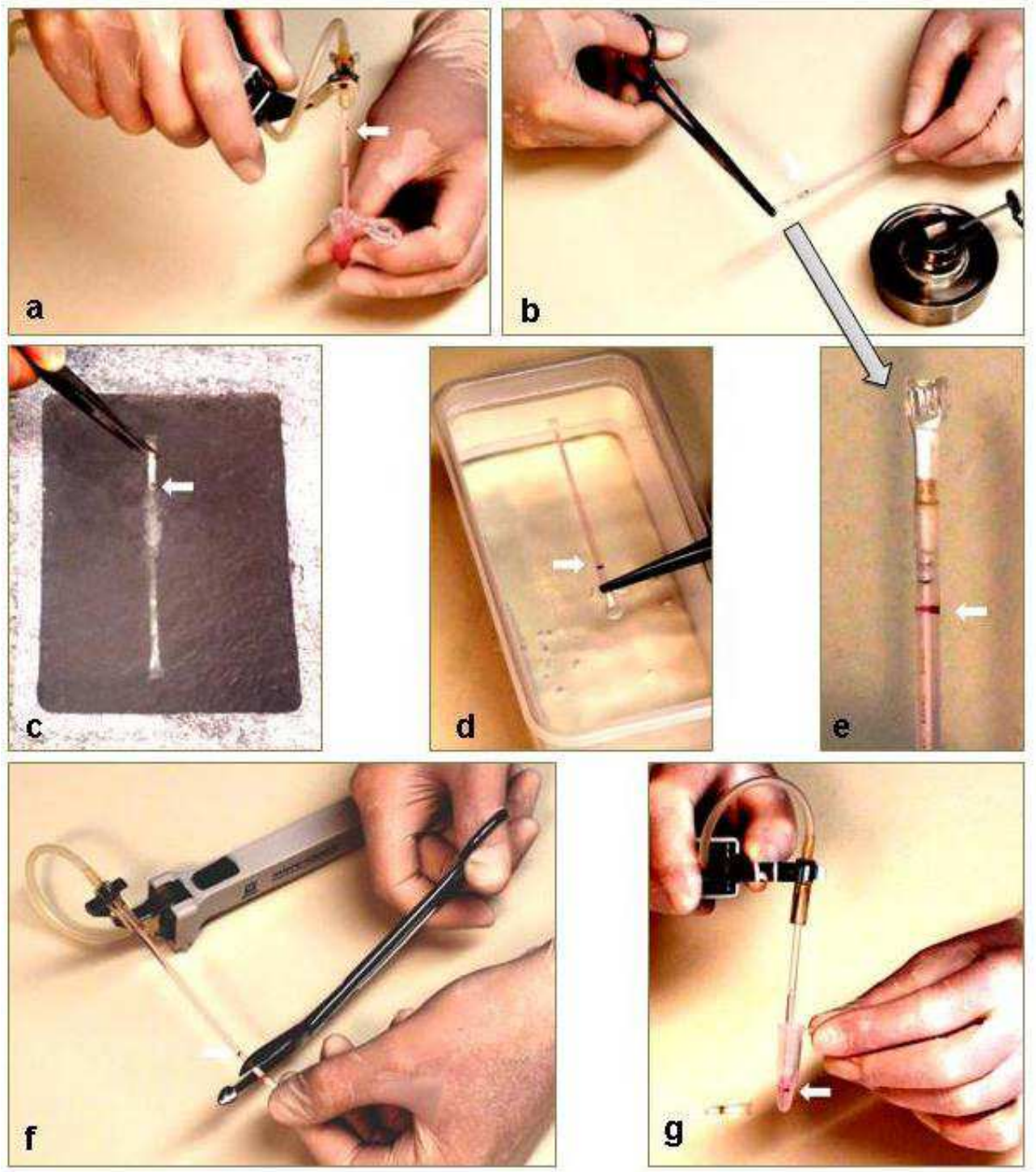

(Arrows) line, (a) aspiration of spermatozoa suspension in straw, (b, e) flame-sealing of straw, (c) cooling of straw, (d) warming of straw, (f) cutting of straw, (g) expelling of spermatozoa suspension from straw.

Fig. 6. Schema of human spermatozoa vitrification using $0.5 \mathrm{~mL}$ straws.

33258 staining technique (Kay et al. 1994). The results of that comparative investigation have shown that motility of spermatozoa vitrified in large volume $(500 \mu \mathrm{L})$ in absence of permeable cryo-protectants displayed statistically higher levels of motility as compared to slow conventional freezing $(76.0+4.7 \%$ vs $52.0+3.9 \%$, respectively, $\mathrm{P}<0.05$; in fresh $85.0+$ 
$5.1 \%$ ) as well as after 24 and 48 hours in vitro culture (Figure 7). It was observed, that higher rates of membrane integrity (Figure 8 ) were achieved in vitrified sperm as compare to slow conventional freezing ( $54.0 \pm 5.0 \%$ vs $28.3 \pm 3.5 \%$, respectively, $\mathrm{P}<0.05)$, but lower then in non-treated fresh control $(98.2 \pm 0.5 \%, \mathrm{P}<0.05)$. The effect of two procedures used for cryopreservation on sperm functional state as assessed by CTC staining is shown on Figure 8. There was a statistically significant difference between percentages of spermatozoa with intact acrosome after vitrification as compared to conventional freezing ( $44.4 \pm 4.5 \%$ vs 30.0 $\pm 3.9 \%$, respectively, $\mathrm{P}<0.05)$, but statistically lower then in fresh non-treated samples $(95.4$ $\pm 5.0 \%$; $<0.05$ ). There were no statistically significant difference between percentages of sperm identified as 'capacitated' in CTC staining after vitrification as compared to conventional freezing $(10.0 \pm 1.8 \%$ vs $11.0 \pm 1.1 \%$, respectively, $\mathrm{P}<0.01)$, but significantly higher in fresh non-treated control $(4.0 \pm 0.2 \%, \mathrm{P}<0.05)$. Described technology has a massive potential for applications in reproductive assisted procedures (ICSI, IVF and IUI) not only because of its simplicity but also because this procedure can effectively protect these cells from cryo-injures, at a level at least comparable to conventional freezing as judged by basic parameters of spermatozoa quality.

This cryoprotectant-free vitrification technology for the cryopreservation of spermatozoa instead traditional slow freezing with permeable cryoprotectants is already used in following centers: our university maternal hospital (www.uniklinik-ulm.de): IVF Centers in Temuco, Chile (about 200 IUI cycles/year) and in Ulm, Germany (www.kinderwunschulm.de) (about 1,000 IVF cycles/year). First successful pregnancies and birth of healthy babies after insemination of vitrified spermatozoa has been recently achieved with vitrified spermatozoa (Isachenko et al., 2011d; Sanchez et al., 2011a).

In conclusion, a basic protection from cryo-injury can be achieved for human spermatozoa using the novel technology of aseptic cryoprotectant-free vitrification in large volumes.

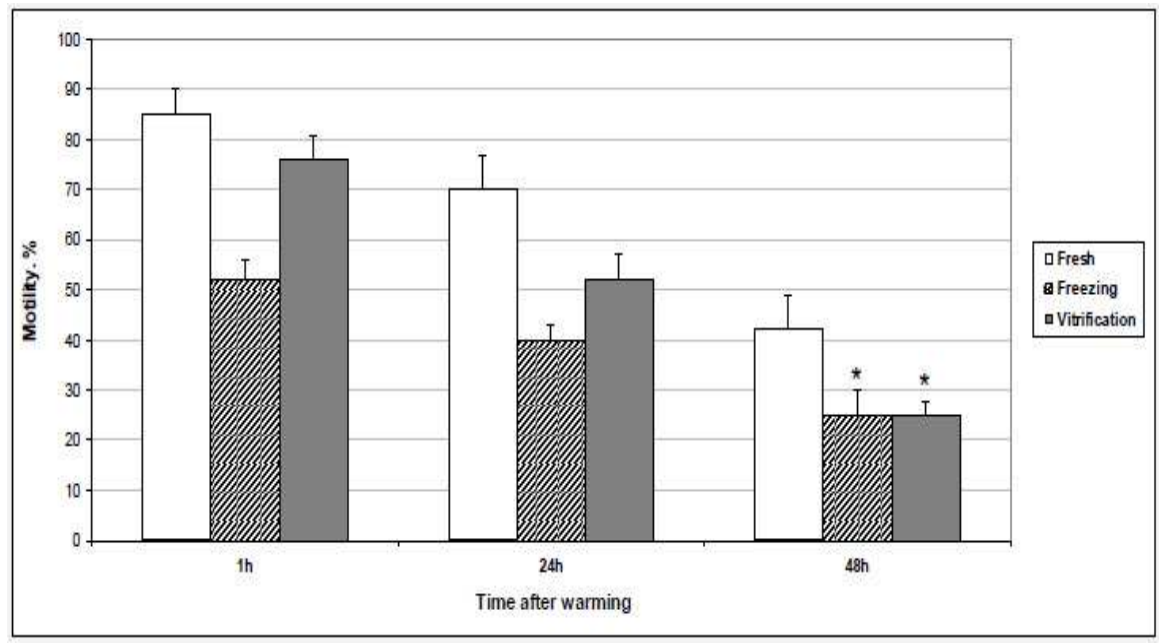

All rates in respective groups are significantly different $(\mathrm{P}<0.05)$ instead columns marked with asterisks $(\mathrm{P}>0.1)$.

Fig. 7. Motility of human spermatozoa after conventional freezing and vitrification. 

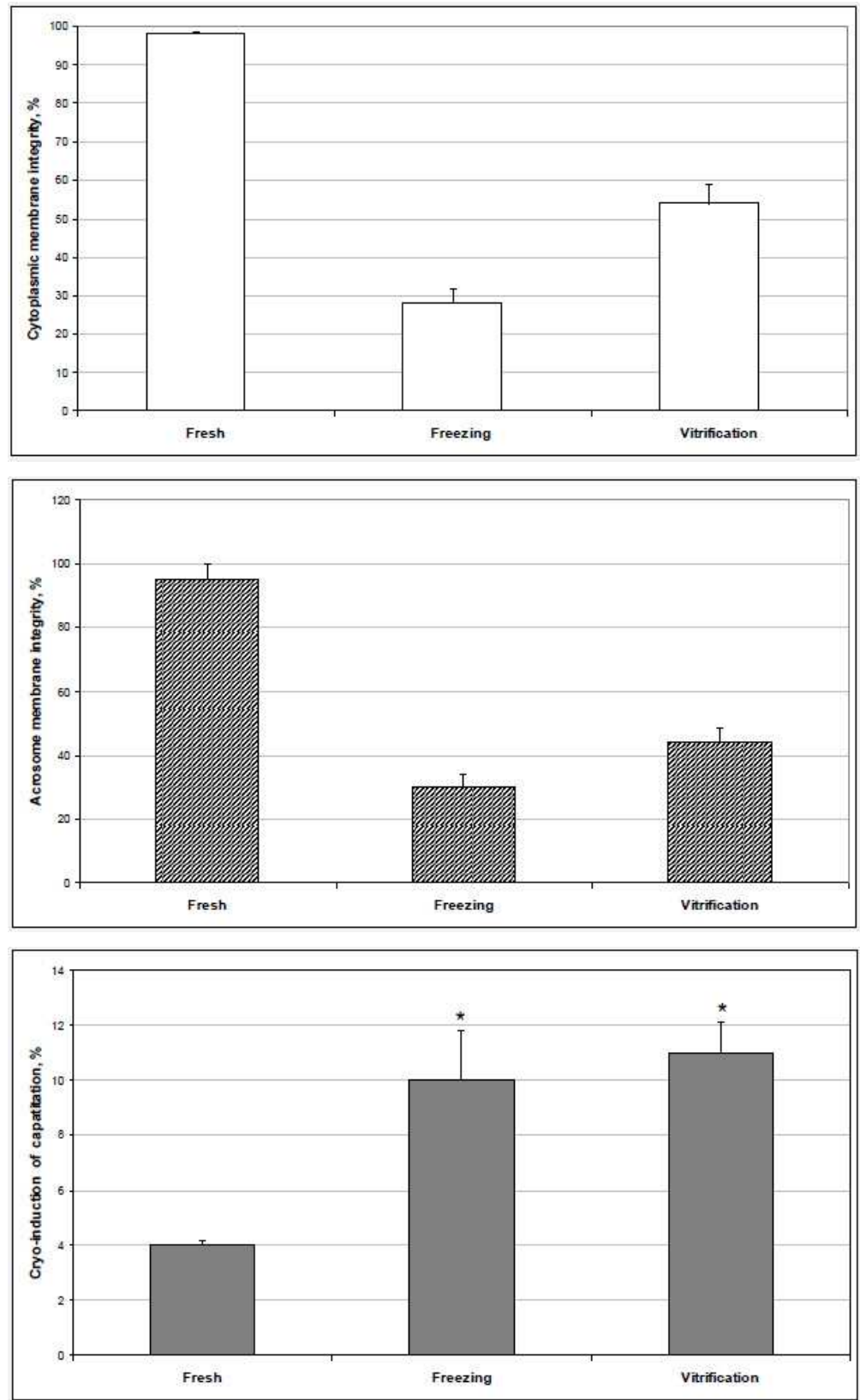

All rates in respective groups are significantly different $(\mathrm{P}<0.05)$ instead columns marked with asterisks $(\mathrm{P}>0.1)$.

Fig. 8. Cytoplasmic and acrosomal membranes integrity as well as cryo-induction of capacitation of human spermatozoa after conventional freezing and vitrification. 


\section{Technology for vitrification of dog spermatozoa (Sánchez et al, 2011)}

If we will investigate the history of reproductive cryobiology we will see that all routine-used technique, excluding intracytoplasmic sperm injection, was firstly approved on the animal model. The same happened and with vitrification technique. After first promising investigation with frog (Luyet and Hodapp, 1938), human (Jahnel, 1938; Parkes, 1945) fowl (Schaffner, 1942) and human, and rabbit (Hoagland and Pincus1942) spermatozoa the vitrification technique was successful re-discovered in 2002 (Nawroth et al., 2002) on human spermatozoa. Recently we have decided to extrapolate the results of our investigation on animal model, thus we have with high attention examined the work of Watson and Plummer (Watson and Plummer, 1985) about responses of spermatozoa from different kind of animals to cold shock. According to this work most sensitive to cold injury are spermatozoa of animals, which produce gametes with big blade-shaped flat head. The spermatozoa of human, stallion, dog and cat have the highest stability to cold shock due to smallest blade-shaped flat head compare to the rabbit spermatozoa (have middle stability), ram, bull and boar (have the lowest stability to cold shock). Took into account these data we have decided, that the spermatozoa from human, stallion, dog and cat could be similar well preserved using vitrification technique. In this case we have decided to investigate the ability of dog spermatozoa, which stay on third place after human one according to head's size, to maintain their physiological function after vitrification without use of permeable cryoprotectants. In cryobiological routine practice, carbohydrates were already used for sperm cryopreservation (Nakagata, Takeshima, 1992, 1993; Wakayama et al., 1998). It has been suggested that raffinose plays the role of a membrane stabilizing and dehydrating agent. Comparative investigation of three different sugars, monosaccharide glucose, disaccharide sucrose and trisaccharide raffinose, showed that protection against freezing/thawing injuries is independent of the kind of sugar itself, but depends more on the sugar's concentration (Koshimoto \& Mazur, 2002). Based on this evidence, we have decided to investigate the different concentrations of sucrose on the viability of cryopreserved spermatozoa. However, the problem was that the dog spermatozoa have the special physiological property which connect to capacitation process. It is well known that spermatozoa of different kind mammalian species are very sensitive to the negative effect of cryoprotectants dependent on temperature (Sánchez \& Schill, 1991; Deppe et al., 2004). It is also proved (Pérez et al., 1996) that low survival and fertilizing capacity of cryopreserved mammalian spermatozoa has been attributed to an early state of capacitation resulting from the procedures by which spermatozoa are preserved. These kind of changes have been called as 'early state capacitation' or 'cryocapacitation'. These data of Pérez and colleagues (Pérez et al., 1996) later were supported (Samper, 1997; Maxwell et al., 1997). These authors showed the negative effect of cryocapacitation on the fertilizing capacity and viability of spermatozoa. The described study showed that the canine spermatozoa starts rapidly with capacitation process as soon as have been separated from seminal plasma with subsequent $20-40 \%$ of capacitated and spontaneous acrosome reacted spermatozoa in culture media. This rate is higher than in other mammals (Risopatrón et al., 2002; Santiani et al., 2004) and the spermatozoa are therefore more affected by the cryocapacitation process than those of other species. Probably the sperm membrane in this species is especially sensitive to cooling in the range of temperatures between $20^{\circ} \mathrm{C}$ and $5^{\circ} \mathrm{C}$ and to heating to $30^{\circ} \mathrm{C}$ at thawing (Holt \& North, 1991; Sánchez \& Schill, 1991). In this case for dog spermatozoa which are high sensitive to capacitation the cryopreservation protocol with a very increased cooling speed should be used, because these temperature ranges by ultra-rapid freezing (vitrification) will be just eliminated. 
Took into account all mentioned above in our investigation (Sánchez et al., 2011b) to decrease the sensitivity of dog spermatozoa to different manipulations before cryopreservation we have chosen the Human tubal fluid (HTF, Quinn et al., 1985) as basic medium, which was served as control. The centrifugation for removing seminal plasma before dilution with cryoprotective media and subsequent cryopreservation at $700 \mathrm{~g}$ for 6 min was performed. This allowed us to achieve very high $(\sim 80 \%)$ amount of spermatozoa with intact acrosome in control.

(Figure 9). Integral membrane proteins are associated with the lipid bilayer and their function may be expected to be altered, especially those that perform the function of transport channels for calcium absorption. The permeability of these channels is increased on cooling, affecting calcium regulation (Robertson \& Watson, 1986; Robertson et al., 1988). These facts have serious consequences for cell function (Bailey \& Bhur, 1994) and many changes may be incompatible with sperm viability. In this case we have decided to apply to dog spermatozoa the early developed us vitrification protocol (Isachenko et al., 2008) for human sperm cells. The following tested groups were compared: HTF (Control); HTFbovine serum albumin (BSA, $1 \%$ end-concentration); HTF-BSA + $0.1 \mathrm{M}$ sucrose; HTF-BSA + $0.25 \mathrm{M}$ sucrose and HTF-BSA + 0.4 M sucrose.

The vitrification procedure was done as follow. Briefly, aliquots of $30 \mu \mathrm{l}$ of sperm suspension (different vitrification media) were dropped directly into $\mathrm{LN}_{2}$. After solidification, the spheres were packaged in cryotubes and stored for at least $24 \mathrm{~h}$ in liquid nitrogen before use. The warming was performed by quickly submerging spheres one by one (not more than five spheres) in $5 \mathrm{ml}$ of $\mathrm{HTF}-\mathrm{BSA} 1 \%$ pre-warmed to $37^{\circ} \mathrm{C}$ accompanied by gentle agitation for $5-10 \mathrm{sec}$. The post-thaw sperm suspension was maintained at $37^{\circ} \mathrm{C}$ and $5 \% \mathrm{CO}_{2}$ for $10 \mathrm{~min}$ and then centrifuged at $300 \mathrm{~g}$ for $5 \mathrm{~min}$. The cell pellet was finally resuspended in $50 \mu \mathrm{l}$ of HTF only for sperm evaluation.

The influence of tested media on the following physiological parameters of dog spermatozoa we have checked with such screening methods: viability and condition of acrosome with double stain technique (Trypan blue-Giemsa) with subsequent evaluation of acrosome pattern according to Didion (Didion et al., 1989); DNA fragmentation was detected with using of TUNEL technique (Gorczyca et al., 1993); detection of the change in mitochondrial permeability was done according to Smiley (Smiley et al., 1991); the motility of spermatozoa was checked as well.

According to our investigtion the percentage of spermatozoa with acrosome-intact membrane was high in all treatment groups (Figure 9) independent from concentration of sucrose in vitrification solution, but lower then in control $(\mathrm{P}<0.05)$.

The best progressive motility after warming (Figure 10) was significantly increased in the sperm vitrified with $0.25 \mathrm{M}$ sucrose and 1\% BSA (42.5 $\pm 2.3 \%)$, compared to other treatment groups $(\mathrm{P}<0.01)$. However, lower or higher concentration of sucrose did not significantly improve the progressive motility post-vitrification. Comparable results $(60.7 \%$ of motility) was reported (Tsutsui et al., 2003) when the dog semen was chilled in egg yolk- ${ }^{* *}$ Tris at $4^{\circ} \mathrm{C}$ for over 4 days, but the spermatozoa lost their fertilizing capacity.

The presence of sucrose in vitrification solution independent from the concentration has strong positive influence on viability of spermatozoa (Figure 10) and was $\sim 70 \%(\mathrm{P}<0.001)$ for all sucrose-treatment groups. 


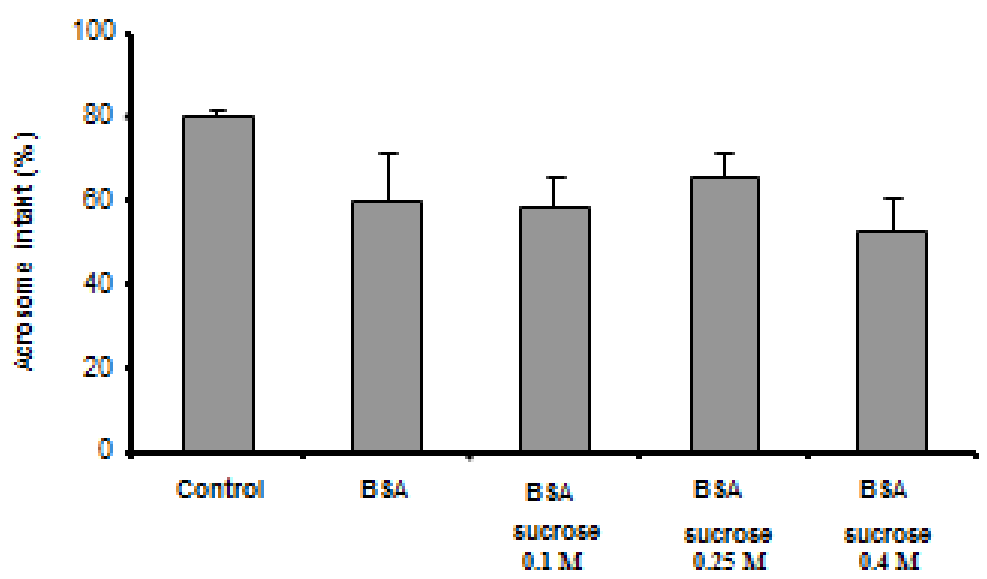

Fig. 9. Acrosome intact in canine spermatozoa after vitrification with $1 \%$ BSA and different concentrations of sucrose. Percentage of acrosome intact spermatozoa was determined by dual stain (Trypan blue- Giemsa). Data are expressed as mean \pm SD from six experiments. Control $=$ Sperm vitrified with medium HTF only. BSA, bovine serum albumin.

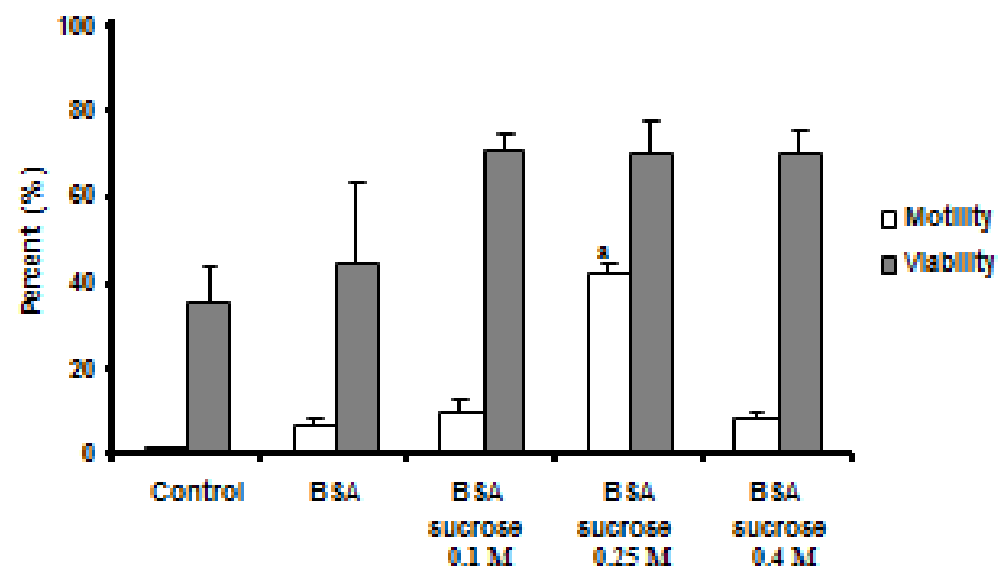

Fig. 10. Progressive motility and viability of canine spermatozoa after vitrification with $1 \%$ BSA and different concentrations of sucrose. Motility was determined by microscopic examination using a phase contrast microscope and viability by dual stain (Trypan blueGiemsa). Data are expressed as mean \pm SD from six experiments. A significant difference with respect to the control is indicated by a $(\mathrm{P}<0.01)$. Control: Sperm vitrified with medium HTF only. BSA, bovine serum albumin.

Our data have shown that the vitrification significantly protect the sperm DNA (Figure 11) against fragmentation when used $0.25 \mathrm{M}$ sucrose in combination with $1 \%$ BSA compare to control $(97,2 \pm 0.5 \%$ vs $94,4 \pm 0.6 \%$, respectively, $\mathrm{P}<0.05)$. However, the lower $(0.1 \mathrm{M})$ as 
well as higher concentrations $(0.4 \mathrm{M})$ of sucrose had not significantly protective effect against DNA fragmentation. These data support our previous results (Isachenko et al., $2004 a, b$, the vitrification medium included only 1\% HSA) and we can assume that vitrification itself due to very fast speed of cooling can provide protective effect on DNA and protect against fragmentation. It is very important results, because damage of DNA in sperm is strongly correlated with mutagenic events (Moreno et al., 2004) and how have showed Paasch with colleagues (Paasch et al., 2004) cryopreservation and thawing can be associated with varying extent of activation of apoptotic machinery in human spermatozoa. The danger is that such spermatozoa are still able to fertilize the oocyte, however, the mutations and defects did not possible to discover until the embryo has divided and the fetus has developed (Twigg et al., 1998). At present exist the opinion that DNA decondensation or fragmentation may occur in different magnitudes, which will depend on the process or the kind of cryoprotectant used (Schuffner et al., 2001; Chohan et al., 2004; Ngamwuttiwong \& Kunathikom, 2007; Yildiz et al., 2007). Unfortunately, until now this question is still open, because it is not entirely clear what the effect of cryopreservation on DNA integrity is, and what would be the ideal conditions of slow freezing to reduce this effect. In this case the method of vitrification is more successful, because allows to obtain low levels of DNA fragmentation by protection due to applying of very high speed of cooling and exclusion of permeable cryoprotectants from vitrification solution.

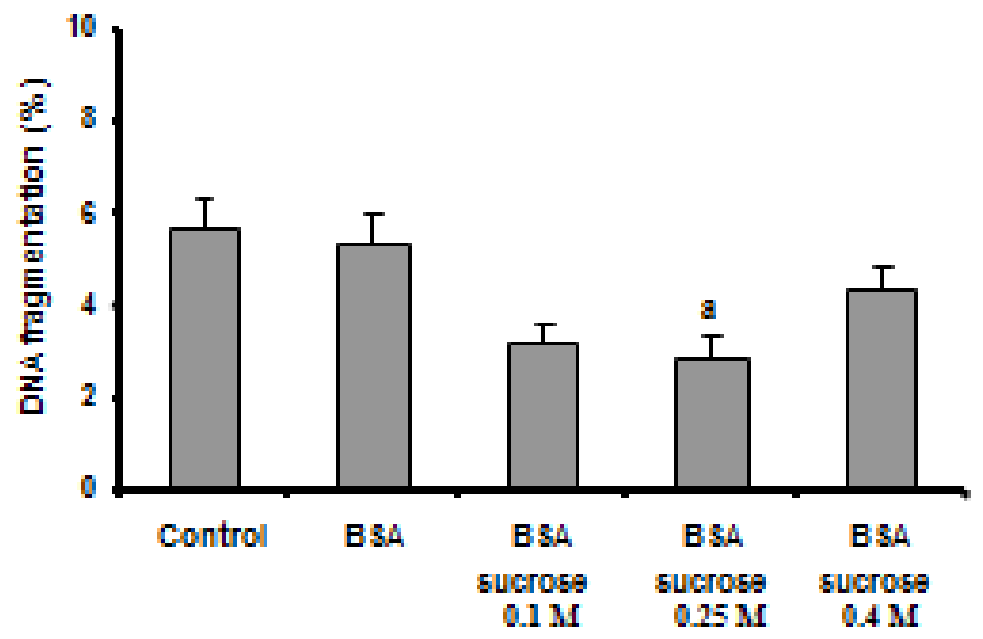

Fig. 11. DNA fragmentation in canine sperm after vitrification with $1 \% \mathrm{BSA}$ and different concentrations of sucrose. DNA fragmentation was determined by the TUNEL assay. Data are expressed as mean \pm SD from six experiments. A significant difference with respect to the control is indicated by a $(\mathrm{P}<0.05)$. Control: Sperm vitrified with medium HTF only. BSA, bovine serum albumin.

Fragmentation DNA has been interpreted at present as apoptosis or apoptosis-like events (Paasch et al., 2004). This has been verified in cryopreserved / thawed sperm, with presence of increased caspase's activity induced by cryopreservation (caspase-3, -8, -9), decreased $\mathrm{M}$ $\Delta \Psi$ due to release of regulating proteins associated with mitochondria, evidence of DNA 
fragmentation, externalization of phosphatidylserine in the plasma membrane (Paasch et al., 2004) and production of reactive oxygen substances (Roca et al., 2005). Among the first events that occur in early apoptosis are changes in mitochondrial permeability which alter the transmembrane potential $(\mathrm{M} \Delta \Psi)$. Changes in the $\mathrm{M} \Delta \Psi$ are caused by the insertion of proapoptotic proteins within the membrane, and oligomerisation may create pores, dissipating the transmembrane potential and thus releasing cytochrome $\mathrm{c}$ into the cytoplasm (Zamzami et al., 1995). In our work (Figure 12) we achieved the reduction of apoptotic-like process in canine spermatozoa and have got after warming more then $40 \%$ of spermatozoa with intact $\mathrm{M} \Delta \Psi$ using of the vitrification solution with $0.25 \mathrm{M}$ sucrose and $1 \%$ BSA compare to other treatment groups $(\mathrm{P}<0.001)$.

These results have demonstrated that vitrification without the use of permeable cryoprotectants allows to avoid the cryoprotectants toxicity caused by their addition and removal with subsequent negative effects on the spermatozoa genome. The use of sucrose in concentration of $0.25 \mathrm{M}$ in combination with $1 \% \mathrm{BSA}$ and ultrarapid speed of cooling can effectively preserve important physiological parameters of canine spermatozoa.

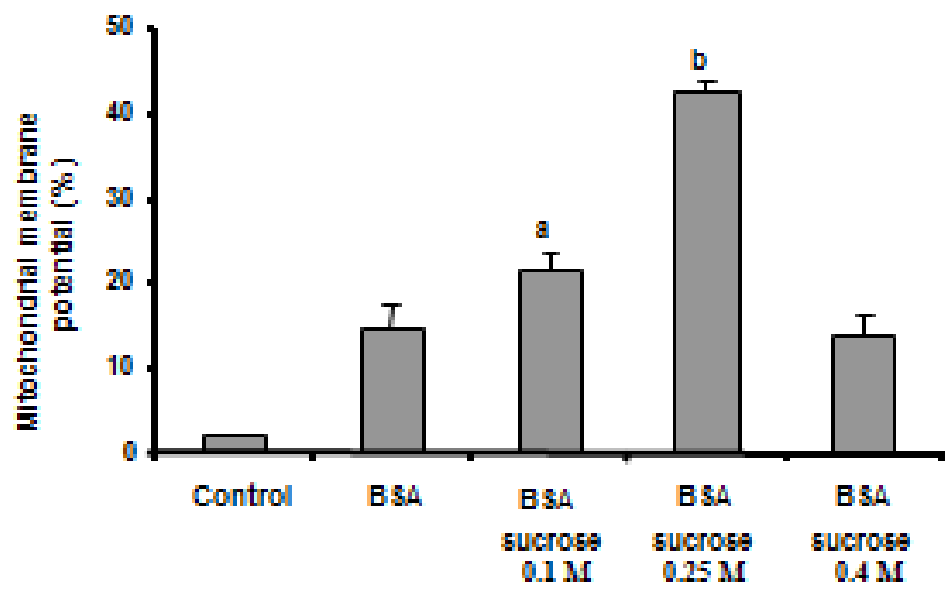

Fig. 12. Integrity of mitochondrial membrane potential in canine spermatozoa after vitrification with $1 \%$ BSA and different concentrations of sucrose. Mitochondrial membrane potential was determined by staining with the cationic fluorescent JC-1. Data are expressed as mean $\pm \mathrm{SD}$ from six experiments. A significant difference with respect to the control is indicated by a $(\mathrm{P}<0.05)$ and $\mathrm{b}(\mathrm{P}<0.01)$. Control: Sperm vitrified with medium HTF only. BSA, bovine serum albumin.

\section{New technology for vitrification of fish (Oncorhynchus mykiss) spermatozoa Merino et al., 2011a, b.}

At the beginning of this sub-chapter we would like to mention that the fish spermatozoa of both sea and river fish species have a very special peculiarities compare to all mammalian species. The fish sperm cells are homogenous; all spermatozoa can be activated at the same time and then swim with very similar characteristics at a certain time point post-activation. In many fish species, the flagellum is $50-60 \mathrm{~mm}$ long with a ribbon shape (presence of fins) 
instead of cylindrical; thus, the flagellum appears brighter by dark-field microscopy, allowing clear visualization of wave shapes (Cosson et al. 2008). Just for knowledge, the head of investigated us rainbow trout spermatozoa is ovoid-shaped, measuring about $3 \times 1.3$ $\mu \mathrm{m}$ in diameter and possess any acrosome. In middle piece present only one mitochondrial body (several mitochondria are sometimes identified in the middle piece, but later during evolution they are fused together) is shaped like an incompletely closed ring. The middle piece is completely separated from the flagellum by an invagination of the cell membrane, which reaches from the head to the base (Billard, 1983; Tuset et al., 2008). During spermatogenesis, sperm cells are prepared for accomplishing their fertilizing task for which they need to fully exploit their swimming ability immediately and as fast as possible in order to encounter the egg. The initial velocity is very high at activation, but motility duration lasts for periods ranging only $40 \mathrm{~s}$ to $20 \mathrm{~min}$ as an energetic consequence of the high velocity (Cosson et al. 2008). As possible to see the fish spermatozoa are much different from mammalian one.

Since the first successful cryopreservation of herring sperm 50 years ago (Blaxter, 1953) considerable improvement has been achieved in sperm cryopreservation and developed technology of conventional freezing of fish spermatozoa has been used in agricultural practice very broadly (Scott and Baynes, 1980; Stoss and Holtz, 1981; Dreanno et al., 1997; Wheeler and Thorgaard, 1991; Conget et al., 1996; Lahnsteiner et at., 2000; Fabbrocini et al., 2000; Zhang et al., 2003; Chen et al., 2004; Viveiros and Godinho, 2009). Usually, for protection of spermatozoa from the negative effects of low temperatures caused by conventional freezing ('slow', with controlled rate of cooling), permeable cryoprotectants are used. At present, applied cryobiology practically always uses only four permeable cryoprotectants: three spirits (ethylene glycol, propylene glycol and glycerol) and the highly polarized organic solvent dimethyl sulfoxide. However, as reported for mammalian spermatozoa, these cryoprotectants can produce osmotic and cytotoxic effects, including parthenogenesis (Gilmore et al., 1997). And for fish spermatozoa these problems are still very actual, because post-thaw viability and fertility of the cryopreserved sperm are reduced dramatically as a result of accumulated cellular damage that arise throughout the freezingthawing process. The same like for other species the cryopreservation results in considerable damage to cellular structures such as plasma membrane, nucleus, mitochondria, and flagellum (Lahnsteiner et al., 1992; 1996; Drokin et al., 1998; Conget et al., 1996; Zhang et al., 2003). So, according to Ogier de Baulny (Ogier de Baulny, 1997) the percentage of spermatozoa with an intact membrane and a functional mitochondrion after cryopreservation varied below $18 \%$ only. According to our results which we have achieved on human spermatozoa (Isachenko et al. 2003, 2004a,b, 2005, 2008, 2011a, b, c, d) and dog (Sánchez et al., 2011b) with applying of cryoprotectant-free vitrification protocol we have decided to investigate the method on fish spermatozoa (Oncorhynchus mykiss) (Merino et al., 2011a, b). This decision we have got because the authors of these studies were able to establish statistically higher motility and in vitro fertilization ability of vitrified spermatozoa compared with spermatozoa cryopreserved using conventional slow freezing.

The standard Cortland ${ }^{\circledR}$ culture medium (Trus-Cott et al., 1968) for fish spermatozoa (per liter: $1.88 \mathrm{~g} \mathrm{NaCl}, 0.23 \mathrm{~g} \mathrm{CaCl} 2,7.2 \mathrm{~g} \mathrm{KCl}, 0.41 \mathrm{~g} \mathrm{NaH} 2 \mathrm{PO} 4,1 \mathrm{~g} \mathrm{NaHCO}, 0.23 \mathrm{~g} \mathrm{MgSO} 47 \mathrm{H} 2 \mathrm{O}, 1.0 \mathrm{~g}$ Glucose, 10\% Glycol and 10\% Tris Base and prepared to $\mathrm{pH} 8$ at 268mOsm) was used for all manipulation and served as control. Fresh-retrieved semen was diluted 1:3 in the non-activating Cortland ${ }^{\circledR}$ medium with subsequent determination of the motility and concentration by phase- 
contrast microscopy. Subjective evaluations of motility were performed by placing $2 \mu \mathrm{l}$ of this sperm suspension on a glass slide and immediately adding $10 \mu \mathrm{l}$ of the activator Powermilt ${ }^{\circledR}$ (Católica of Temuco University, Chile) at $10^{\circ} \mathrm{C}$. The motility of the spermatozoa was observed in $12 \mu \mathrm{l}$ sperm activated by subjective microscopic examination under phase contrast optics at 400x magnification. Motility assessments were made in triplicate for each sample at $5 \mathrm{~s}$ following activation with Powermilt ${ }^{\circ}$. Sperm concentrations were determined with a Neubauer hemocytometer after dilution of $1 \mu \mathrm{l}$ of sperm suspension in $1200 \mu \mathrm{l}$ of standard culture medium. Only samples with high motility $\left(>80 \%\right.$ ) and concentration $12 \times 10^{9}$ spermatozoa/mL (Drokin et al., 1998) were used in this study.
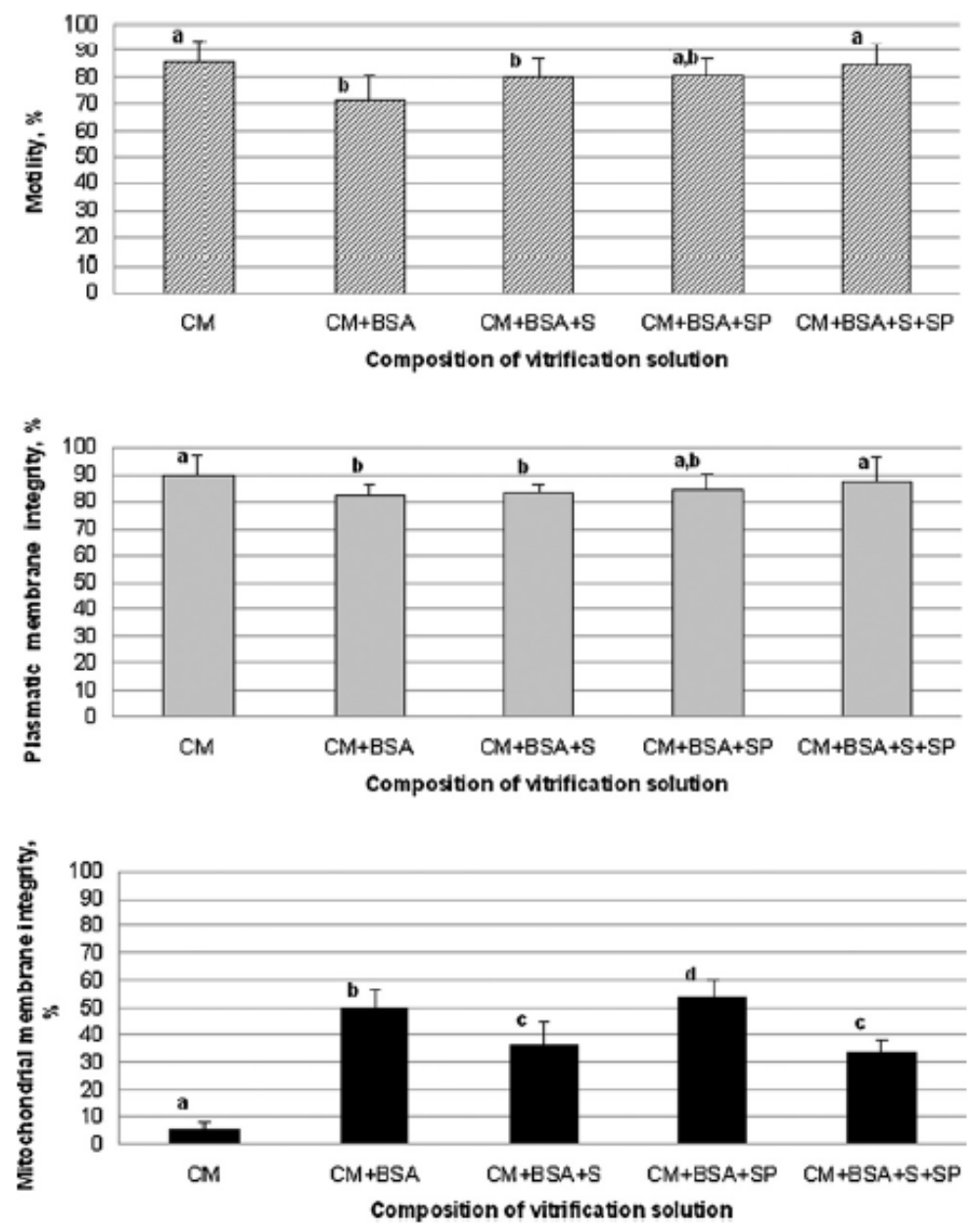

Fig. 13. Motility, cytoplasmic membrane integrity and mitochondrial membrane integrity of vitrified rainbow trout spermatozoa. (CM) Cortland $^{\circledR}$, (BSA) $1 \%$ bovine serum albumin, (SP) $40 \%$ of seminal plasma, (S) $0.125 \mathrm{M}$ sucrose. Different superscripts indicate statistical difference between respective values of compared groups $(\mathrm{P}<0.05)$. 
In our work we have investigated the following five treatments groups (Figure 13):

Group 1: Cortland® medium only (frozen control)

Group 2: Cortland ${ }^{\circledR}$ medium $+1 \%$ BSA

Group 3: Cortland ${ }^{\circledR}$ medium $+1 \%$ BSA $+0.125 \mathrm{M}$ sucrose

Group 4: Cortland ${ }^{\circledR}$ medium $+1 \%$ BSA $+40 \%$ seminal plasma

Group 5: Cortland ${ }^{\circledR}$ medium+ 1\% BSA + 40\% seminal plasma + 0.125M sucrose.

The vitrification / warming of rainbow spermatozoa was proceeded as following:

Sperm samples were centrifuged at $300 \mathrm{~g}$ for $10 \mathrm{~min}$ at $4{ }^{\circ} \mathrm{C}$. The seminal plasma (supernatant) was retained and the sperm suspension diluted with Cortland ${ }^{\circledR}$ medium to a concentration of $40 \times 10^{6}$ spermatozoa/ml. Five equal $500-\mu l$ aliquots from each preparation were placed in individual $1 \mathrm{ml}$ tubes for vitrification. Twenty microliters of sperm suspension from each tube was dropped directly into liquid nitrogen, during which the droplet adopted a spherical form approximately $3 \mathrm{~mm}$ in diameter. After $5 \mathrm{~min}$, the solidified droplets were placed into 2-ml cryovials pre-cooled in liquid nitrogen with precooled tweezers. After storage for at least $24 \mathrm{~h}$ in liquid nitrogen, the samples were warmed by plunging the droplets into a $15 \mathrm{ml}$ tube containing $5 \mathrm{ml}$ Cortland ${ }^{\circledR}$ medium supplemented with $1 \% \mathrm{BSA}$ at $37^{\circ} \mathrm{C}$ with intense agitation. After warming (one droplet/tube), the tubes were maintained at $37^{\circ} \mathrm{C}$ for $5-10$ min prior to evaluation of spermatozoa quality.

The spermatozoa quality was tested according the following parameters:

- Motility - (percent of motile spermatozoa detected during $30 \mathrm{~s}$ after warming) was performed using phase contrast microscope (Carl Zeiss Jena, Jena, Germany);

- Cytoplasmic membranes integrity was assessed using the LIVE/DEAD Sperm Viability Kit (SYBR-14 dye; Invitrogen Inc., Eugene, OR, USA) and propidium iodide. The analysis of spermatozoa was carried out under an epifluorescence microscope (Axiolab drb KT 450905, Zeiss) at 400x magnification (Figure 14).

- Mitochondrial membranes integrity (mitochondrial activity) was assessed due to relative levels of $M \Delta \Psi$ using the fluorescent cationic dye, JC-1 (5,50,6,60-tetrachloro-110,3,30-tetraethylbenzamidazolocarbocyanin iodide, according to the manufacturer's protocol (MIT-E-_TM, BIOMOL® International LP, Plymouth Meeting, PA, USA) and observed under epifluorescent optics (Axiolab drb KT 450905) at 400x magnification at room temperature. For the MIT-E- $\Psi$ reagent, an excitation/emission filter of $488 / 490 \mathrm{~nm}$ was used. The monomeric dye structure emits at 527nm (Green FITC channel), whereas J-aggregates indicative of high potential of undamaged mitochondria emit at $590 \mathrm{~nm}$ (red, RITC channel). If $\Delta \Psi \mathrm{m}$ is above a certain $\mathrm{mV}$ threshold, JC-1 monomers multimerize into a crystalline-like state that shifts the emission spectrum to higher frequencies (orange-red) and it is the multimerization of the monomer that is potential sensitive, the paracrystals can be stable after formation, which is why we can still get red fluorescence in JC- 1 treated cells after collapsing $\Delta \Psi \mathrm{m}$ with inhibitors, which is why staining is done after inhibitor treatment (Figure 15).

To investigate these cold sensitive (Holt, 2000; O'Connell et al., 2002) organelles of spermatozoa were necessary because the retention of plasma membrane integrity and 
mitochondrial function after cryopreservation is too important with regard to fertilization capacity of both spermatozoa and oocytes (Gao et al., 1997; de Lamirande et al., 1997). For all species, normal mitochondrial function is a key factor in the fertilizability of spermatozoa and for fish it is especially critical to maintain mitochondrial activity because high motility normally lasts for only $30 \mathrm{~s}$ to few minutes. Spermatozoa of rainbow trout have only one mitochondrion to produce sufficient ATP to drive this transient high motility, and damage during cryopreservation will certainly lead to decrease of motility and as a result, fertilization ability (Maisse, 1996). In this case the stability of mitochondrion during cryopreservation can be used as a specific test for applicability of a any investigated cryopreservation protocol (Meseguer et al., 2004; O'Connell et al., 2002).

The results of this investigation showed that the proportion of sperm showing normal, high motility varied between $82 \%$ and $95 \%$ in fresh samples. In Groups 1, 2, 3, 4, and 5, motility in these solutions was $86 \%, 71 \%, 79 \%, 81 \%$, and $82 \%$, respectively (Figure 13).

The percent of spermatozoa with intact cytoplasmic membrane after thawing was similar between the 5 experimental groups, ranging from $81.8 \%$ to $90 \%$, as shown in Figures 13 and 14. Nevertheless, the integrity of mitochondrial membrane potential of spermatozoa (Figures 13 and 15) in Groups 1, 2, 3, 4, and 5 was decreased significantly compare to non

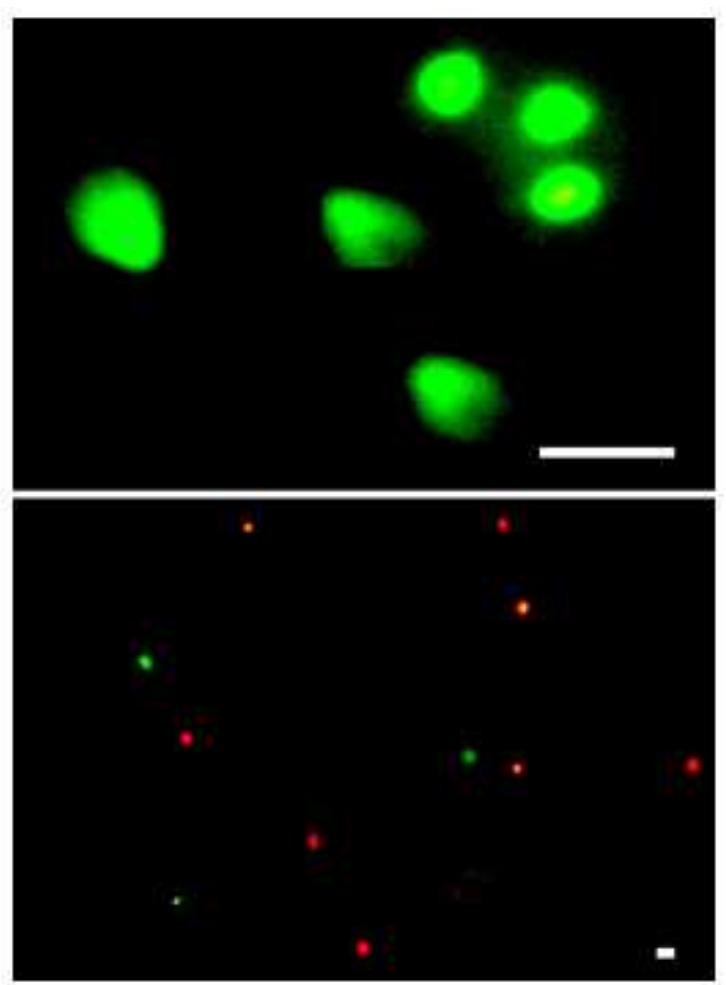

Fig. 14. Example of rainbow trout spermatozoa with non-damaged (green) and damaged (red) cytoplasmic membranes. Bar $=8 \mu \mathrm{m}$. 


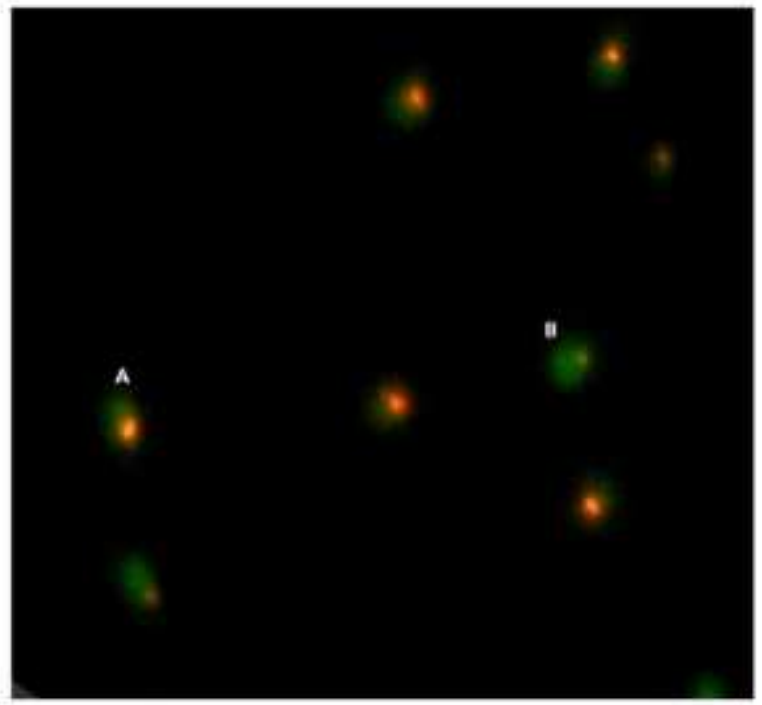

Fig. 15. Example of rainbow trout spermatozoa with (A) non-damaged and (B) damaged mitochondria. Bar $=2.5 \mu \mathrm{m}$.

treated spermatozoa $(5.5 \%, 49.8 \%, 37.1 \%, 54.7 \%$, and $34.4 \%$, respectively). As possible to see from our results they can have the following potential question. How spermatozoa can have a high level of motility with low level of the integrity of mitochondrial membranes? Especially this question is actual taking into account that fish spermatozoa have only one mitochondrion. A lower $\mathrm{M} \Delta \Psi$, as reflected by green fluorescence, simply can have the following explanation. Activity of the mitochondria, including ATP production, is reduced when compared to their red counterparts. Cell often have "green" and "red" mitochondria with shifts between all green or all red governed by a variety of external and internal conditions, and this is normal. Individual mitochondria constantly shift from red to green and back to red in response to rapid changes in local conditions, including calcium levels and $\mathrm{pH}$ (Vanblerkom, personal communication). While the plasma membrane is known to be sensitive to cryopreservation (Cabrita et al., 2001; Aitken and Baker, 2006; Muller et al., 2008), our results shows that it is cryostable in rainbow trout sperm, as indicated by $\sim 90 \%$ of non-damaged plasmatic membrane in sperm vitrified in culture medium only i.e., without permeable cryoprotectants and additional proteins). This is similar to levels reported after conventional freezing with permeable cryoprotectants. We suggest that the vitrification technique described here which associated with high rate of cooling allows to avoid the formation of large extracellular water crystals. Sucrose is well known to have a beneficial influence on the plasma membrane of cells subjected to cryopreservation (Anchordoguy et al., 1987; Rodgers and Glaser, 1993). For human spermatozoa, the drop-wise technique of vitrification is a major technical advance because it includes a mixture of non-permeable cryoprotectants such as serum albumin (Isachenko et al., 2008). However, we report that the 
inclusion of sucrose in the vitrification solution was ineffective for rainbow trout spermatozoa. According to Lahnsteiner (2007), lipoproteins in the seminal plasma of rainbow trout likely maintain the lipid composition of the plasma and may increase the cryostability of spermatozoa. Our results support this point of view and we suggest that the method of sperm vitrification described here could also be applied to other species. As a rule, carbohydrates are used for sperm cryopreservation to compensate for the decrease in osmotic pressure caused by the permeable cryoprotectant glycerol, which works as an additional dissolvent and has the ability to decrease the medium's osmotic pressure. Based on this evidence, we investigated whether sucrose had a similar cryoprotective effect on fish spermatozoa during freeze-thaw. We found that its inclusion in vitrification medium has no visible protective effect on mitochondrial membrane integrity nor does it provide significant protection for spermatozoa when compared to other vitrification mediums containing BSA or BSA + seminal plasma. Indeed, the addition of these non-permeable cryoprotectants did not increase either the motility or plasma membrane integrity of rainbow trout spermatozoa. However, described here technology of cryopreservation of fish spermatozoa by direct plunging into liquid nitrogen has big disadvantage because did not protect the biological material against direct contact with liquid nitrogen. In this connection in the future investigation it would be necessary to find a synthetic substitute for seminal plasma to avoid the possible microbial contamination. In fact, any technology in reproductive biology, and especially in a therapeutic medical approach, must guarantee the full protection of cells from microorganisms that might survive in liquid nitrogen temperatures (Gardner, 1998; Bielanski et al., 2003), and it has been suggested that liquid nitrogen can be contaminated by microorganisms (Tedder et al., 1995). The problem of potential microbial contamination of spermatozoa during cryopreservation, especially by the virus of Infectious Salmon Anemia is significant in the fish industry, especially in Latin America (Ellis, 2007; Fortt and Buschmann, 2007; Sommer, 2009). In spite of that the results of our experiments conformed that for fish spermatozoa the developed method of cryopreservation by direct plunging into liquid nitrogen (vitrification) without permeable cryoprotectants is potentially significant for this industry, but the development of "aseptic" methods, in which the spermatozoa suspension is enclosed in capillaries or straws to prevent direct contact of sperm with liquid nitrogen, will need to be considered. Filtration or ultraviolet treatment of liquid nitrogen cannot guarantee the absence of contamination of biological material by viruses. For example, Tedder et al. (1995) reported the contamination of blood probes by hepatitis virus during the storage of probes in liquid nitrogen. Different types of viruses, such as hepatitis virus, papova virus, vesicular stomatitis virus and herpes virus, which are simple and very cryostable structures, may increase their virulence after direct plunging and storage in liquid nitrogen (Hawkins et al., 1996; Charles and Sire, 1971; Schaffer et al., 1976; Jones and Darville, 1989).

\section{General conclusion}

Data presented in this review shown that the technique of cryopreservation by direct plunging into liquid nitrogen (vitrification) in absence of permeable cryoprotectants has a great perspective. This technique allows significantly protect the important physiological parameters of mammalian and fish spermatozoa against cryo-injures. 


\section{References}

Aitken RJ and Clarkson JS. Cellular basis of defective sperm function and its association with the genesis of reactive oxygen species by human spermatozoa. J Reprod Fertil 1987;81:459-469.

Aitken RJ, Baker MA. Oxidative stress, sperm survival and fertility control. Mol Cell Endocrinol 2006;250:66-69.

Anchordoguy T, Rudolph A, Carpenter J, Crowe J. Mode of interaction of cryoprotectants with membrane phospholipids during freezing. Cryobiology 1987;24:324-331.

Andrews FC. Colligative properties of simple solutions. Science 1976;194:567-571.

Bailey JL, Bhur MM. Cryopreservation alters the Ca2 + flux of bovine spermatozoa. Can J Anim Sci 1994;74:45-51.

Billard R. Ultrastructure of trout spermatozoa: Changes after dilution and deep-freezing. Cell Tissue Res 1983; 228:205-218.

Barbas JP, Mascarenhas RD. Cryopreservation of domestic animal sperm cells. Cell Tissue Bank 2009;10:49-62.

Bielanski A, Bergeron H, Lau PCK, Devenish J. Microbial contamination of embryos and semen during long term banking in liquid nitrogen. Cryobiology 200346:146-152.

Blaxter J H S. Sperm storage and cross-ertilization of spring and autumn spawning herring. Nature 1953;172:1 189-1 190.

Cabrita E, Ane L, Herraez M. Effect of external cryoprotectants as membrane stabilizers on cryopreserved rainbow trout sperm. Theriogenology 2001;56:623-635.

Cervera R, Garcia-Xime'nez F. Vitrification of zona-free rabbit expanded or hatching blastocysts: a possible model for human blastocysts. Hum Reprod 2003;18:21512156.

Charles GN, Sire DJ. Transmission of papova virus by cryotherapy applicator. J Am Med Assoc 1971;218:1435.

Chen S L, Ji XS, Yu GC, Tian YS, Sha ZX. Cryopreservation of sperm from turbot (Scophthalmus maximus, and application to large-scale fertilization. Aquaculture 2004; 236: 547-556.

Chen S, Lien Y, Cheng Y, Chen H, Ho H, Yang Y. Vitrification of mouse oocytes using closed pulled straws (CPS) achieves a high survival and preserves good patterns of meiotic spindles, compared with conventional straws, open pulled straws (OPS) and grids. Hum Reprod 2001;16:2350-2356.

Chohan KR, Griffin JT, Carrell DT. Evaluation of chromatin integrity in human sperm using acridine orange staining with different fixatives and after cryopreservation. Andrologia 2004;36:321-326.

Conget P, Fernfindez M, Herrera G, Minguell JJ. Cryopreservation of rainbow trout (Oncorhynchus mykiss) spermatozoa using programmable freezing. Aquaculture 1996;143:319-329.

Cormier N, Bailey JL. A differential mechanism is involved during heparin- and cryopreservationinduced capacitation of bovine spermatozoa. Biol Reprod. 2003; 69:177-185.

Cosson J, Groison A-L, Suquet M, Fauvel C, Dreanno C, Billard R. Marine fish spermatozoa: racing ephemeral swimmers. Reproduction 2008;136 277-294 
Critser JK, Huse-Benda AR, Aaker D, Arneson BW, Ball GD. Cryopreservation of human spermatozoa. III. The effect of cryoprotectants on motility. Fertil Steril 1988;50:314320.

de Lamirande E, Leclerc P, Gagnon C. Capatitation as a regulatory event that primes spermatozoa for the acrosome reaction and fertilization. Mol Hum Reprod 1997;3:175-194.

Deppe M, Ortloff C, Salinas G, Bravo D, Sánchez R. Efecto de la temperatura de incubación y adición de glicerolsobre la preservación del acrosoma en espermatozoides humanos. Rev Invest Clin 2004;56:477-482.

Didion BA, Dobrinsky JR, Giles JR, Graves CN. Staining procedure to detect viability and the true acrosome reaction in spermatozoa of various species. Gamete Res 1989;22:51-57.

Dreanno C, Suquet M, Quemener L, Cosson J, Fierville F, Normant Y, Billard R. Cryopreservation of turbot (Scophthalmus Maximus) spermatozoa. Theriogenology 1997; 48: 589-603.

Drokin S, Stein H, Bartscherer H. Effect of cryopreservation on the fine structure of spermatozoa of rainbow trout (Oncorhynchus mykiss) and brown trout (Salmo trutta F. fario). Cryobiology 1998;37:263-270.

Ellis S. Risk and factors salmon chilean. Assessing infectious disease emergence potential in the U.S. Aquacult Industr 2007,1-111. www.scribd.com/doc/1446078/USDAaquaculture23.

Fabbrocini A.S, Lavadera L, Rispoli S, Sansone G. Cryopreservation of Seabream (Sparus aurata) Spermatozoa. Cryobiology 2000;40: 46-53.

Fraga CG, Motchnik PA, Shigenaga MK, Helbock HJ, Jacob RA, Ames BN. Ascorbic acid protects against endogenous oxidative DNA damage in human sperm. Proc Nat Acad Sci USA. 1991;88:11003-11006.

Franks F. Biological freezing and cryofixation. J Microsc 1977;111:3-16.

Fortt Z, Buschmann AR. Residuos de tetraciclina y quinolonas en peces silvestres en una zona costera donde se desarrolla la acuicultura del salmón en Chile. Rev Chil Infect 2007;24:8-12.

Gao D, Mazur P \& Critser J 1997 Fundamental cryobiology of mammalian spermatozoa. In Reproductive Tissue Banking, 4 edn, pp 263-328. Eds AM Karow \& JK Critser. London: Academic Press

Gardner DK. Development of serum-free media for the culture and transfer of human blastocysts. Hum Reprod 1998;13:218-225.

Gilmore JA, Liu J, Gao DY, Critser JK. Determination of optimal cryoprotectants and procedures for their addition and removal from human spermatozoa. Hum Reprod 1997;12:112-118.

Glander HJ, Schaller J. Hidden effects of cryopreservation on quality of human spermatozoa. Cell Tissue Bank 2000;1:133-42.

Gorczyca W, Traganos F, Jesionowska H, Darzynkiewicz Z. Presence of DNA strand breaks and increased sensitivity of DNA in situ to denaturation in abnormal human sperm cells; analogy to apoptosis of somatic cells. Exp Cell Res 1993;207:202-205.

Green CE, Watson PF. Comparison of the capacitation-like state of cooled boar spermatozoa with true capacitation, Reproduction 2001;122: 889-898. 
Hammadeh ME, Askari AS, Georg T, Rosenbaum P, Schmidt W. Effect of freeze-thawing procedure on chromatin stability, morphological alteration and membrane integrity of human spermatozoa in fertile and subfertile men. Int J Androl 1999;22:155-162.

Hawkins AE, Zuckerman MA, Briggs M, Gilson RJ, Goldstone AH, Brink NS, Tedder RS. Hepatitis B nucleotide sequence analysis: linking an outbreak of acute hepatitis B to contamination of a cryopreservation tank. J Virol Methods 1996;60:81-88.

Henkel R, Ichikawa T, Sánchez R, Miska W, Ohmori H, Schill WB. Differentiation of ejaculates showing reactive oxygen species production by spermatozoa or leukocytes. Andrologia 1997;29:295-301.

Henkel RR, Schill WB. Sperm preparation for ART. Reprod Biol Endocrinol 2003;1:108.

Henkel R, Kierspel E, Stalf T, Mehnert C, Menkveld R, Tinneberg HR, Schill WB, Kruger TF. Effect of reactive oxygen species produced by spermatozoa and leucocytes on sperm functions in non-leucocytospermic patients. Fertil Steril 2005;83:635-642.

Henkel R, Bastiaan HS, Schüller S, Hoppe I, Starker W, Menkveld R. Leucocytes and intrinsic ROS production may be factors compromising sperm chromatin condensation status. Andrologia 2010;42:69-75.

Hoagland H, Pincus G. Revival of mammalian sperm after immersion in liquid nitrogen. J Gen Physiol 1942;25:337-344.

Holt W, North RD. Cryopreservation, actin localization and thermotropic phase transitions in ram spermatozoa. J Reprod Fertil 1991;91:451-461.

Holt WV. Fundamental aspects of sperm cryobiology: the importance of species and individual differences. Theriogenology 2000;53:47-58.

Isachenko E, Isachenko V, Katkov II, Dessole S, Nawroth F. Vitrification of mammalian spermatozoa in the absence of cryoprotectants: from past practical difficulties to present success. Reprod Biomed Online 2003;6:191-200.

Isachenko, E., Isachenko, V., Katkov, I.I., Rahimi, G., Schondorf, T., Mallmann, P., Dessole, S., Nawroth, F. (2004a). DNA integrity and motility of human spermatozoa after standard slow freezing versus cryoprotectant-free vitrification. Hum. Reprod. 19, 932-939.

Isachenko, V., Isachenko, E., Katkov, I.I., Montag, M., Dessole, S., Nawroth, F., van der Ven, H. (2004b). Cryoprotectant-free cryopreservation of human spermatozoa by vitrification and freezing in vapor: effect on motility, DNA integrity, and fertilization ability. Biol. Reprod. 71, 1167-1173.

Isachenko V, Isachenko E, Montag M, Zaeva V, Krivokharchenko A, Nawroth F, Dessole S, Katkov I, Van der Ven H. Clean technique for cryoprotectant - free vitrification of human spermatozoa. Reprod Biomed Online 2005a;10:350-354.

Isachenko V, Montag M, Isachenko E, van der Ven H Vitrification of mouse pronuclear embryos after polar body biopsy without direct contact with liquid nitrogen. Fertil Steril 2005b; 84:1011-1016.

Isachenko, V., Katkov, I.I., Yakovenko, S., Lulat, A.G., Ulug, M., Arvas, A., Isachenko, E. (2007). Vitrification of human laser treated blastocysts within cut standard straws (CSS): novel aseptic packaging and reduced concentrations of cryoprotectants. Cryobiology 54, 305-309.

Isachenko E, Isachenko V, Weiss JM, Kreienberg R, Katkov II, Schulz M, Lulat AG, Risopatron MJ, Sanchez R. Acrosomal status and mitochondrial activity of human spermatozoa vitrified with sucrose. Reproduction 2008;136:167-173. 
Isachenko E, Isachenko V, Sánchez R, Katkov II, Kreienberg R. Cryopreservation of spermatozoa: old routine and new perspective. In: Donnez J, Kim SS, eds. Principles and Practice of Fertility Preservation. Cambridge, UK: Cambridge University Press, 2011a:177-198.

Isachenko V, Isachenko E, Petrunkina A.M., Sánchez R. Human spermatozoa vitrified in the absence of permeable cryoprotectants: birth of two healthy babies. Reprod Fertil Dev. 2011b, 24:323-326.

V. Isachenko, R. Maettner, A. M. Petrunkina, K. Sterzik, P. Mallmann, G. Rahimi, R. Sánchez, J. Risopatrón, I. Damjanoski, E. Isachenko. Vitrification of Human ICSI/IVF Spermatozoa Without Cryoprotectants: New Capillary Technology. J Androl., 2011c. In press

Isachenko V, Maettner R, Petrunkina AM, Sterzik K, Mallmann P, Rahimi G, Sánchez R, Risopatrón J, Hancke K, Damjanoski I, Kreienberg R, Isachenko E. Cryoprotectantfree Vitrification of Human Spermatozoa in Large (to $0.5 \mathrm{~mL}$ ) Volume: Novel Technology. Clin Lab. 2011d, 57:643-650.

Jahnel F. Resistance of human spermatozoa to deep cold, Klinische Wochenschrift 1938;17:1273-1274.

Jones SK, Darville JM. Transmission of virus-particles by cryotherapy and multi-use caustic pencils: a problem to a dermatologist? Br J Dermatol 1989;121:481-486.

Karlsson JOM, Cravalho EG. A model of diffusion-limited ice growth inside biological cells during freezing. J Appl Phys 1994;75:4442-55.

Katkov II, V Isachenko, E Isachenko, M S. Kim, A G-M.I. Lulat, A M. Mackay, F Levine. Low- and high-temperature vitrification as a new approach to biostabilization of reproductive and progenitor cells. Int J Refrigeration 2006;29:346-357.

Kay VJ, Coutts JR, Robertson L. Effects of pentoxifylline and progesterone on human sperm capacitation and acrosome reaction. Hum Reprod 1994;9:2318-2323.

Koshimoto C, Gamliel E, Mazur P. Effect of osmolality and oxygen tension on the survival of mouse sperm frozen to various temperatures in various concentrations of glycerol and raffinose. Cryobiology 2000;41:204-31.

Kumar R, Venkatesh S, Kumar M, Tanwar M, Shasmsi MB, Kumar R, Gupta NP, Sharma RK, Talwar P, Dada R. Oxidative stress and sperm mitochondrial DNA mutation in idiopathic oligoasthenozoospermic men. Indian J Biochem Biophys. 2009;46:172177.

Koshimoto $\mathrm{CH}$, Mazur P. Effects of cooling and warming rate to and from $-70^{\circ} \mathrm{C}$, and effect of further cooling from -70 to $-196^{\circ} \mathrm{C}$ on the motility of mouse spermatozoa. Biol Reprod 2002;66:1477-1484.

Kuleshova LL, MacFarlane DR, Trounson AO, Shaw JM. Sugars exert a major influence on the vitrification properties of ethylene glycol-based solutions and have a low toxicity to embryos and oocytes. Cryobiology 1999;38:119- 130.

Lahnsteiner F, Berger B, Horvath A, Urbanyi B, Weismann T. Cryopresevation of spermatozoa in cyprindid fishes. Theriogenology 2000;54:1 477-1 496.

Lahnsteiner F, Weismann T, Patzner RA. Fine structural changes in spermatozoa of the grayling, Thymallus thymallus (Pisces: Teleostei), during routine cryopreservation. Aquaculture 1992;103: 73-84. 
Lahnsteiner F, Berger B, Wiesmann T, Patzner R. Changes in morphology, physiology, metabolism, and fertilization capacity of rainbow trout semen following cryopreservation. Prog Fish Cult 1996;58:149-159.

Lahnsteiner F. Characterization of seminal plasma proteins stabilizing the sperm viability in rainbow trout (Oncorhynchus mykiss). Anim Reprod Sci 2007;97:151-164.

Larson JM, McKinney KA, Mixon BA, Burry KA, Wolf DP. An intrauterine inseminationready cryopreservation method compared with sperm recovery after conventional freezing and post-thaw processing. Fertil Steril 1997;68:143-8.

Levin RL. A generalized method for the minimization of cellular osmotic stresses and strains during the introduction and removal of permeable cryoprotectants. J Biomech Eng 1982;104:81-86.

Lozina-Lozinski LK. Action of cooling on cells and the body as a multifactorial process. Tsitologiya 1982;24:371-390.

Luyet BJ, Hoddap A. Revival of frog's spermatozoa vitrified in liquid air. Proc Meet Soc Exp Biol 1938;39:433-434.

Maisse G. Cryopreservation of fish semen: a review. In: Proceedings of Refrigeration and Aquaculture, Bordeaux, France, 1996March, pp. 443-466.

Mazur P. Kinetics of water loss from cells at subzero temperatures and the likelihood of intracellular freezing. J Gen Physiol 1963;47:374-369.

Maxwell WMC, Welch GR, Johnson LA. Viability and membrane integrity of spermatozoa after dilution and flow cytometric sorting in the presence or absence of seminal plasma. Reprod Fertil Dev 1997;8:1165-1178.

McLaughlin EA, Ford WC, Hul MG. A comparison of the freezing of human semen in the uncirculated vapour above liquid nitrogen and in a commercial semiprogrammable freezer. Hum Reprod 1990;5:724-8.

Merino O, Risopatrón J, Sánchez R, Isachenko E, Figueroa E, Valdebenito I, Isachenko V. Fish (Oncorhynchus mykiss) spermatozoa cryoprotectant-free vitrification: Stability of mitochondrion as criterion of effectiveness. Animal Reproduction Science Animal Reproduction Science 2011;124:125-131.

Merino O, Sánchez R, Risopatrón J, Isachenko E, Katkov II, Figueroa E, Valdebenito I, Mallmann P, Isachenko V. Cryoprotectant-free vitrification of fish (Oncorhynchus mykiss) spermatozoa: first report. Andrologia 2011;1-6.

Meseguer M, Garrido N, Martinez-Conejero JA, Simon C, Pellicer A, Remohi J. Role of cholesterol, calcium, and mitochondrial activity in the susceptibility for cryodamage after a cycle of freezing and thawing. Fertil Steril 2004;82:514-515.

Moreno D, Fuentes JL, Sánchez A, Baluja L, Prieto E. Conversión y reversión génica en saccharomyces cerevisiae. Un modelo para el estudio del dano producido por radiacio 'n gamma. Rev Cubana Invest Biomed 2004;23:80-86.

Muller K, Muller P, Pincemy G, Kurz A, Labbe C. Characterization of sperm plasma membrane properties after cholesterol modification: consequences for cryopreservation of rainbow trout spermatozoa. Biol Reprod 2008;78:390-399.

Nakagata N, Takeshima T. High fertilizing ability of mouse spermatozoa diluted slowly after cryopreservation. Theriogenology 1992;37:1263-1291.

Nakagata N, Takeshima T. Cryopreservation of mouse spermatozoa from inbred and F 1 hybrid strains. Jikken Dobutsu 1993;42:317-320. 
Nawroth F, Isachenko V, Dessole S, Rahimi G, Farina M, Vargiu N, Mallmann P, Dattena M, Capobianco G, Peters D, Orth I, Isachenko E. Vitrification of human spermatozoa without cryoprotectants, Cryo Lett 23;2002:93-102.

Ngamwuttiwong T, Kunathikom S. Evaluation of cryoinjury of sperm chromatin according to liquid nitrogen vapour method (I). J Med Assoc Thai 2007;90:224-228.

Ogier de Baulny B, Labb C, Maisse G. Membrane integrity, mitochondrial activity, ATP content, and motility of the European catfish (Silurus glanis) testicular spermatozoa after freezing with different Cryoprotectants. Cryobiology 1999;39:177-184.

Paasch U, Sharma RK, Gupta AK, Grunewald S, Mascha EJ, Thomas AJ Jr, Glander HJ, Agarwal A. Cryopreservation and thawing is associated with varying extent of activation of apoptotic machinery in subsets of ejaculated human spermatozoa. Biol Reprod 2004;71:1828-1837.

Perez LJ, Valcarcel A, Delasheras MA, Moses D, Baldassarre H. Evidence that frozen/thawed ram spermatozoa show accelerated capacitation in vitro as assessed by chlortetracycline assay. Theriogenology 1996;46:131-140.

Pérez-Sánchez F, Cooper TG, Yeung $\mathrm{CH}$, Nieschlang E. Improvement in quality of cryopreserved human spermatozoa by swim-up before freezing. Int J Androl 1994;17:115-120.

Parkes AS. Preservation of human spermatozoa at low temperatures, Br Med J 1945;2:212213.

Petrunkina AM, Volker G, Weitze KF, Beyerbach M, Töpfen-Petersen E, Waberski D. Detection of cooling-induced membrane changes in the response of boar sperm to capacitating conditions. Theriogenology 2005;63:2278-2299.

Petrunkina AM. Fundamental aspects of gamete cryobiology. J Reproduktionsmed Endokrinol 2007;4:78-91.

Quinn P, Warnes GM, Kerin JF, Kirby C. Culture factors affecting the success rate of in vitro fertilization and embryo transfer. Ann NY Acad Sci. 1985;442:195-204.

Rall WF, Fahy GM. Ice-free cryopreservation of mouse embryos at )196 _C by vitrification. Nature 1985;313:573-575.

Reed ML, Lane M, Gardner DK, Jensen NL, Thompson J. Vitrification of human blastocysts using the cryoloop method: successful clinical application and birth of offspring. J Assist Reprod Genet 2002; 19:304-306.

Risopatrón J, Catalan S, Miska W, Schill WB, Sànchez R. Effect of albumin and polyvinyl alcohol on the vitality, motility and acrosomal integrity of canine spermatozoa incubated in vitro. Reprod Domest Anim 2002;37:347-351.

Robertson L, Watson PF. Calcium transport indiluted or cooled ram semen. J Reprod Fertil 1986;77:117-185.

Robertson L, Watson PF, Plunner JM. Prior incubation reduces calcium uptake and membrane disruption in boar spermatozoa subjected to cold shock. Cryo Lett 1988; 19:286-293.

Roca J, Rodríguez M, Gil M, Carvajal G, García E, Cuello C, Vásquez J, Emilio A. Survival and in vitro fertility of boar spermatozoa frozen in the presence of superoxide dismutase and/or cabalase. J Androl 2005;26:15-24.

Rodgers W, Glaser M. Distributions of proteins and lipids in the erythrocyte membrane. Biochemistry 1993;32:12591-21298. 
Samper JC. Reproductive anatomy and physiology of the breeding stallion. In: Current Therapy in Large Animal Theriogenology. Younquist RS (ed). WB Saunders, Pennsylvania, 1997; pp. 3-12.

Sánchez R, Schill WB. Influence of incubation time/ temperature on acrosome reaction/sperm penetration assay. Arch Androl 1991;27:35-42.

Sánchez R, Isachenko V, Petrunkina AM, Risopatrón J, Schulz M, Isachenko E. Live Birth after Intrauterine Insemination with Spermatozoa from an Oligo-AsthenoZoospermic Patient Vitrified Without Permeable Cryoprotectants. J Androl 2011a, [Epub ahead of print]

Sánchez R, Risopatrón J, Schulz M, Villegas J, Isachenko V, Kreinberg R, Isachenko E. Canine sperm vitrification with sucrose: effect on sperm function. Andrologia 2011b;43:233-41.

Santiani A, Risopatrón J, Sepúlveda N, Sánchez R. Efecto de la lisofosfatidilcolina en la reacción del acrosoma de espermatozoides caninos. Rev Cient FCV-LUZ 2004;14:311-316.

Sawetawan C, Bruns ES, Prins GS. Improvement of post-thaw sperm motility in poor quality human semen. Fertil Steril 1993;60:706-10.

Schaffner CS. Longevity of fowl spermatozoa in frozen condition, Science 1942;96:337.

Schuffner A, Morshedi M, Oehninger S. Cryopreservation of fractionated, highly motile human spermatozoa: effect on membrane phosphatidylserine externalization and lipid peroxidation. Hum Reprod 2001;16:2148-53.

Silva ME, Berland M. Vitrificación de blastocitos bovinos producidos in vitro con el método Open Pulled Straw (OPS): primer reporte. Arch Med Vet 2004;36:79-85.

Smiley ST, Reers M, Mottola-Hartshorn C, Lin M, Chen A, Smith TW, Steele GD Jr, Chen LB. Intracellular heterogeneity in mitochondrial membrane potentials revealed by a Jaggregate-forming lipophilic cation JC-1. Proc Natl Acad Sci USA 1991;88:36713675.

Sommer M. Acuicultura Insostenible en Chile (unsustainable aquaculture in Chile). Rev Electr Vet 2009;10:1-23, www.veterinaria.org/revistas/redvet/n030309.html.

Stanic P, Tandara M, Sonicki Z, Simunic V, Radakovic B, Suchanek E. Comparison of protective media and freezing techniques for cryopreservation of human semen. Eur J Obstet Gyn RB 2000;91:65-70.

Steer CV, Mills CL, Tan SL, Campbell S, Edwards RG. The cumulative embryo score: a predictive embryo scoring technique to select the opti-mal number of embryos to transfer in an in-vitro fertilization and embryo transfer programme. Hum Reprod 1992;7:117-119.

Trus-Cott B, Idler D, Hoyle R, Freeman H. Sub-zero preservation of Atlantic salmon sperm. J Fish Res Board Can 1968;25:363-372.

Tsutsui T, Tezuka T, Mikasa Y, Sugisawa H, Kirihara N, Hori T, Kawakami E. Artificial insemination with canine semen stored at a low temperature. J Vet Med Sci 2003;65:307- 312 .

Tuset VM, Dietrich GJ, Wojtczak M, Słowińska M, de Monserrat J, Ciereszko A. Relationships between morphology, motility and fertilization capacity in rainbow trout (Oncorhynchus mykiss) spermatozoa. J Appl Ichthyol 2008;24:393-397. 
Twigg JP, Irving DS, Aitken RJ. Oxidative damage to DNA in human spermatozoa does not preclude pronucleus formation at intracytoplasmic sperm injection. Hum Reprod 1998; 13:1864-1871.

Vadnais ML, Roberts KP. Seminal plasma proteins inhibit in vitro- and cooling-induced capacitation in boar spermatozoa. Reprod Fertil Dev. 2010;22:893-900.

Villlegas J, Schulz M, Vallejos V, Henkel R, Miska W, Sánchez R. Indirect immunofluorescence using monoclonal antibodies for the detection of leukocytospermia: comparison with peroxidase staining. Andrologia 2002;34: 6973.

Wakayama T, Whittinhgam DG, Yanagimachi R. Production of normal offspring from mouse oocytes injected with spermatozoa cryopreserved with or without cryoprotection. J Reprod Fertil 1998;112:11-7.

Ward MA, Kaneko T, Kusakabe H, Biggers JD, Whittingham DG, Yanagimachi R. Longterm preservation of mouse spermatozoa after freeze-drying and freezing without cryoprotection. Biol Reprod 2003; 69:2100-2108.

Watson P, Plummer JM. The responses of boar sperm membranes to cold shock and cooling. In: Deep Freezing of Boar Semen. Johnson LA, Larsson K (eds). Swedish University of Agricultural Sciences, Uppsala, Sweden, 1985; pp 113-127.

Wheeler PA, Thorgaard GH. Cryopteservation of rainbow trout semen in large straws. Aquaculture 1991;93:95-100.

World Health Organization. Laboratory Manual for the Examination of Human SemenCervical Mucus Interaction, $4^{\text {th }}$ ed. Cambridge University Press,New York, 1999.

Yildiz C, Ottaviani P, Law N, Ayearst R, Liu L, McKerlie C. Effects of cryopreservation on sperm quality, nuclear DNA integrity, in vitro fertilization, and in vitro embryo development in the mouse. Reproduction 2007;133:585- 595.

Yin HZ, Seibel MM. Human sperm cryobanking. Use of modified liquid nitrogen vapor. J Reprod Med 1999;44:87-90.

Zamzami N, Marchetti P, Castedo M, Zanin C, Vayssiere JL, Petit PX, Kroemer G. Reduction in mitochondrial potential constitutes an early irreversible step of programmed lymphocyte death in vivo. J Exp Med 1995;181:1661- 1672.

Zhang, Y. Z., S. C. Zhang, X. Z. Liu, Y. Y. Xu, C. L. Wang, M. S. Sawant, J. Li and S. L. Chen, 2003. Cryopreservation of flounder (ParaBchthys olivaceus) sperm with a practical methodology. Theriogenology 60: 989-996. 


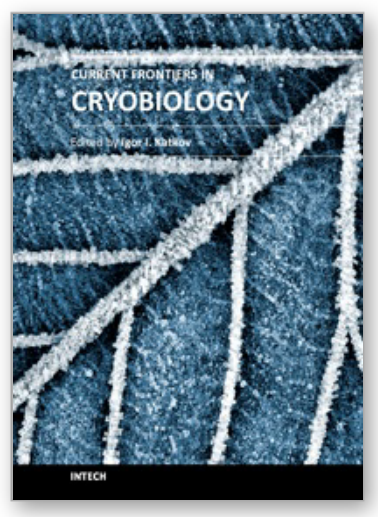

\section{Current Frontiers in Cryobiology}

Edited by Prof. Igor Katkov

ISBN 978-953-51-0191-8

Hard cover, 574 pages

Publisher InTech

Published online 09, March, 2012

Published in print edition March, 2012

Almost a decade has passed since the last textbook on the science of cryobiology, Life in the Frozen State, was published. Recently, there have been some serious tectonic shifts in cryobiology which were perhaps not seen on the surface but will have a profound effect on both the future of cryobiology and the development of new cryopreservation methods. We feel that it is time to revise the previous paradigms and dogmas, discuss the conceptually new cryobiological ideas, and introduce the recently emerged practical protocols for cryopreservation. The present books, "Current Frontiers in Cryobiology" and "Current Frontiers in Cryopreservation" will serve the purpose. This is a global effort by scientists from 27 countries from all continents and we hope it will be interesting to a wide audience.

\section{How to reference}

In order to correctly reference this scholarly work, feel free to copy and paste the following:

E. Isachenko, P. Mallmann, G. Rahimi, J. Risopatròn, M. Schulz, V. Isachenko and R. Sànchez (2012). Vitrification Technique - New Possibilities for Male Gamete Low-Temperature Storage, Current Frontiers in Cryobiology, Prof. Igor Katkov (Ed.), ISBN: 978-953-51-0191-8, InTech, Available from:

http://www.intechopen.com/books/current-frontiers-in-cryobiology/vitrification-of-fish-and-dog-spermatozoa

\section{INTECH}

open science | open minds

\section{InTech Europe}

University Campus STeP Ri

Slavka Krautzeka 83/A

51000 Rijeka, Croatia

Phone: +385 (51) 770447

Fax: +385 (51) 686166

www.intechopen.com

\section{InTech China}

Unit 405, Office Block, Hotel Equatorial Shanghai

No.65, Yan An Road (West), Shanghai, 200040, China

中国上海市延安西路65号上海国际贵都大饭店办公楼 405 单元

Phone: +86-21-62489820

Fax: +86-21-62489821 
(C) 2012 The Author(s). Licensee IntechOpen. This is an open access article distributed under the terms of the Creative Commons Attribution 3.0 License, which permits unrestricted use, distribution, and reproduction in any medium, provided the original work is properly cited. 